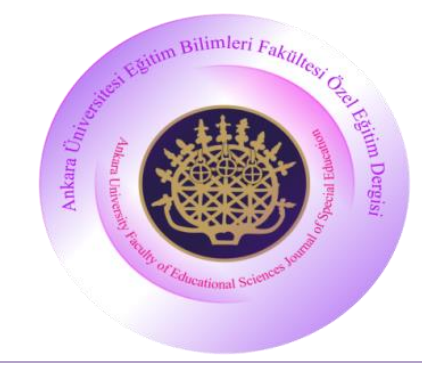

\section{Ankara Üniversitesi Eğitim Bilimleri Fakültesi Özel Eğitim Dergisi}

Yıl: 2018, Cilt: 19, Sayı:1, Sayfa No: 155-180

DOI: 10.21565/ozelegitimdergisi.299494

\title{
Öğrenme Güçlüğü Olan Öğrencilerin Matematik Problemi Çözme Süreçlerinin İncelenmesi: Sesli Düşünme Protokolü Uygulaması
}

\author{
Ufuk Özkubat \\ Gazi Üniversitesi
}

\author{
E. Rüya Özmen \\ Gazi Üniversitesi
}

\begin{abstract}
Öz
Bu çalışmada, öğrenme güçlüğü (ÖG) olan öğrencilerin matematik problemi çözme sürecinde kullandıkları bilişsel ve üstbilişsel stratejilerin değerlendirilmesinde kullanılan sesli düşünme protokolünün (think aloud protocols) tanıtılması amaçlanmıştır. Bu amaç doğrultusunda, ilk olarak, matematik problemi çözmede gerekli olan stratejiler açıklanmış ve ÖG olan öğrencilerin matematik problem çözme güçlüklerine değinilmiş; ikinci olarak, matematik problemi çözmede bilişsel ve üstbilişsel stratejilerin ölçümlenmesinde sesli düşünme protokolünün kullanımı tanıtılmış ve ilgili araştırma bulguları tartışılmıştır. Üçüncü olarak ise sesli düşünme protokolü ile yapılan değerlendirme sonuçlarının öğretime yansımalarına ilişkin bilgiler verilmiştir. Sonuç bölümünde ise ÖG olan öğrencilerin ve akranlarının kullandıkları bilişsel ve üstbilişsel stratejileri inceleyen araştırmaların ihtiyacına değinilerek önerilerde bulunulmuştur.
\end{abstract}

Anahtar sözcükler: Öğrenme güçlüğü, matematik problem çözme, bilişsel ve üstbilişsel stratejiler, sesli düşünme protokolleri.

\section{Önerilen Atıf Sekli}

Özkubat, U., \& Özmen, E. R. (2018). Öğrenme güçlüğü olan öğrencilerin matematik problemi çözme süreçlerinin incelenmesi: Sesli düşünme protokolü uygulaması. Ankara Üniversitesi Eğitim Bilimleri Fakültesi Özel Ĕgitim Dergisi, 19(1), 155-180. doi: 10.21565/ozelegitimdergisi.299494

\footnotetext{
*Sorumlu Yazar: Arş. Gör., Gazi Üniversitesi, E-posta:ufukozkubat@gazi.edu.tr, https://orcid.org/0000-0002-9626-5112

**Prof. Dr., Gazi Üniversitesi, E-posta:ruyaozmen@ hotmail.com, https://orcid.org/0000-0002-0226-1672
} 
Öğrencilerin okul yaşamlarında başarılı olabilmeleri ve toplum içinde bağımsız yaşayabilmeleri için temel akademik becerileri kazanmaları önem taşmaktadır. Öğrencilere kazandırılması hedeflenen temel akademik beceriler; okuma, yazma, temel aritmetik işlemler ve problem çözme olarak sıralanabilir. Matematik problemi çözme, Amerika Ulusal Matematik Kuruluşu tarafından genel ve özel eğitim müfredatının en geniş kısmını oluşturmaktadır (National Council of Teachers of Mathematics [NCTM], 2000). Matematik problemi çözme, ögrrencilerin problem içerisinde yer alan bilgileri analiz ederek ve yorumlayarak, hangi işlemleri kullanacağına ilişkin seçim yapmalarını ve uygulama basamaklarına karar vermelerini gerektirmektedir. Aynı zamanda problem çözme, ögrencilerin matematik kavramlarını nasıl uygulayacaklarını bilme ve hesaplama becerilerini yeni veya farklı ortamlarda kullanmayı da içermektedir (Montague, Applegate ve Marquard, 1993). Dolayısıyla, tüm akademik becerilerde olduğu gibi matematik problemi çözmek amacıyla bu tür işlemleri yerine getirebilmek için bilişsel, üstbilişsel stratejiler ve işlemler kullanılmaktadır (Montague, 1992; Rosenzweig, Krawec ve Montague, 2011; Sweeney, 2010). Problem çözme sürecinde kullanılan bilişsel işlemler; anlama, çevirme, dönüştürme, planlama, tahmin etme, işlem yapma ve değerlendirmedir. Öğrenciler bir problemi çözme sürecinde bilişsel işlemleri gerçekleştirmek için bilişsel stratejiler kullanırlar. Problem çözmede kullanılan bu stratejiler, problemi okuma aşamasından başlayarak, çözümün ve sürecin kontrol edilmesine kadar rol oynar (Montague ve Bos, 1990). Okuma, kendi cümleleri ile ifade etme, görselleştirme, hipotez oluşturma, tahmin etme, hesaplama ve kontrol etmeproblem çözmede kullanılan bilişsel stratejilerdir (Montague, 1992). Matematikte problem çözmede, bilişsel işlemler ve stratejilerle birlikte üstbilişsel işlemler ve stratejiler de önemli rol oynamaktadır. Bu doğrultuda, matematik problemi çözerken öğrencilerin kendi problem çözme uygulamalarını izlemek için kullandıkları üstbilişsel stratejiler, kendini talimatlandırma, kendini sorgulama ve kendini izleme olarak sıralanırken, üstbilişsel işlemler ise strateji bilgisi, kullanımı ve kontrolü olarak betimlenmektedir (Montague, 1992). Alanyazında bilişsel ve üstbilişsel stratejiler incelenirken birarada ele alınması gerektiği çünkü bilişsel ve üstbilişsel stratejilerinin kullanımının herhangi birinde görülen sınırlılığın diğer bileşeni de etkilediği belirtilmektedir (Hallahan ve Kauffman, 2006). Problem çözmede kullanılan bilişsel ve üstbilişsel stratejiler ile işlemler Şekil 1'de gösterilmiştir

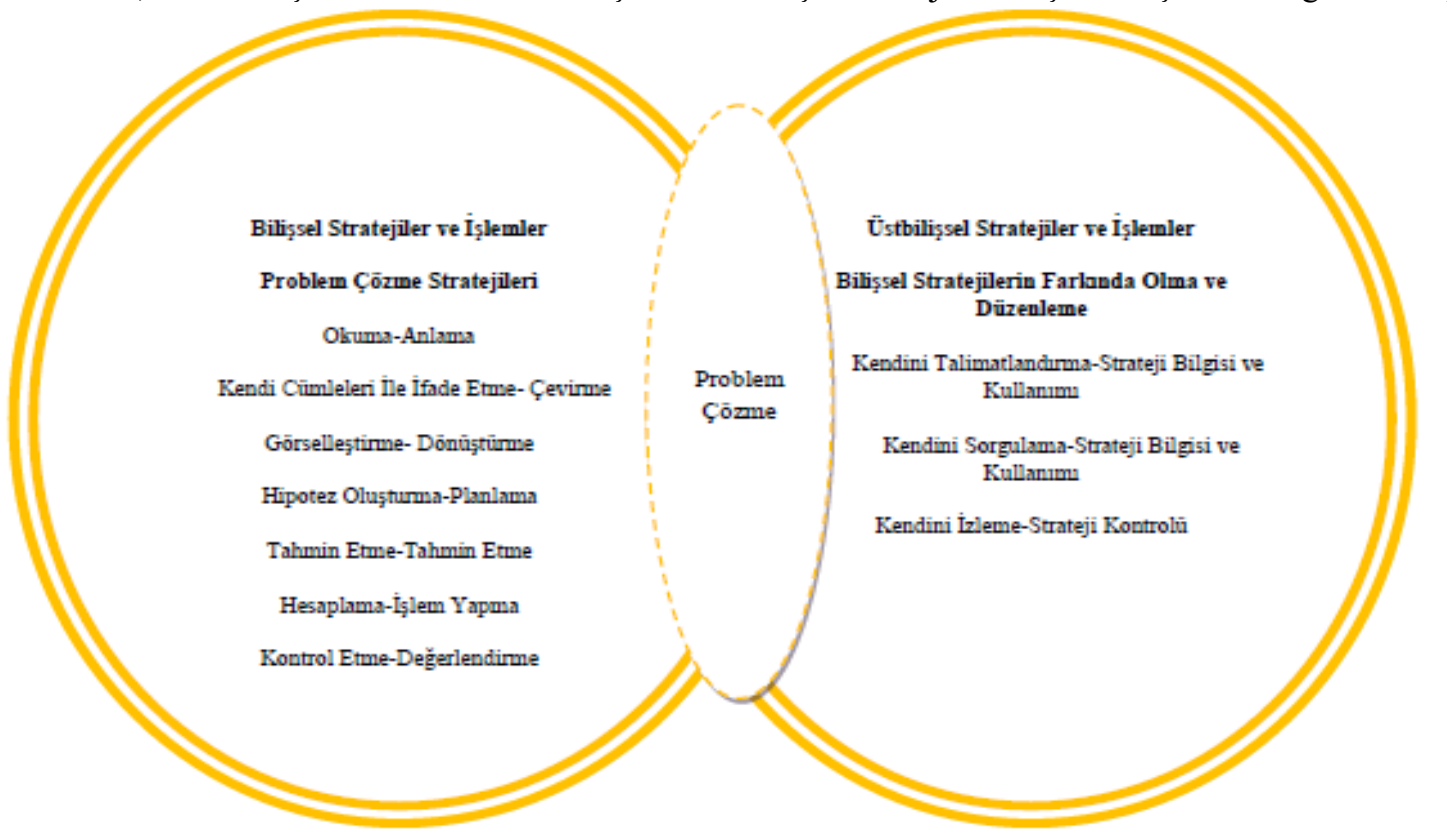

Şekil 1. Montague Matematik Problem Çözme Modeli (1992). 
Öğrenme güçlüğü (ÖG) olan öğrencilerin matematik becerilerinde yaşadıkları sınırlılıklar temel müdahale alanlarından biri olarak ele alınmaktadır (Miller ve Mercer, 1997; Montague, 1992).Temel müdahale alanlarından biri olan matematikte, ÖG olan öğrencilerin sayıları yazmada, temel işlemleri yapmada, işlem basamaklarını hatırlamada, işlemleri uygun adımlarla yapmada problem yaşadıkları ve matematik dili veya terimleri hakkında bilgi eksiklikleri olduğu belirtilmektedir (Bryant ve diğ., 2008; Bryant, Bryant ve Hammill, 2000; Geary, 2004; Kingsdorf ve Krawec, 2014). Ayrıca dil ve okuma becerilerindeki sınırlılıkları, ÖG olan öğrencilerin, ekleme, eksi, elde, değer ve ödünç alma gibi matematik terimlerini karıştırmalarına neden olmaktadır. Matematiğin en temel becerilerinden biri olan problem çözme, ÖG olan öğrencilerin zorlandığı becerilerden biri olarak da betimlenmektedir (Montague, Applegate ve Marquard, 1993).

ÖG olan öğrencilerin problem çözmede yaşadıkları güçlüklerin belirlenmesi amacıyla yapılan araştırmalar bulunmaktadır (Montague ve Applegate, 1993a; Ostad ve Sorenson, 2007; Rosenzweig ve diğ., 2011; Shin ve Bryant, 2015; Swanson, 1990; Swanson ve Jerman, 2006; Sweeney, 2010). Bu bağlamda, ÖG olan öğrencilerin bilişsel performansları ile ilgili olarak Swanson ve Jerman (2006), 1983 ve 2002 yılları arasında yapılmış olan araştırmaları incelemişlerdir. Araştırmalarını, öğrencilerin, sözlü ve görsel uzamsal matematik problemi çözme, uzun süreli bellek, kısa süreli bellek, çalışan bellek ve dikkat değişkenlerini temel alarak sınıflandırmışlardır. Araştırma bulguları incelendiğinde, ÖG olan öğrencilerin aynı gelişimsel yaşta bulunan normal gelişim gösteren akranlarına göre daha düşük bilişsel düzeye sahip oldukları bulunmuştur. Shin ve Bryant (2015), ÖG olan ve olmayan öğrencilerin matematik ve bilişsel performanslarını değerlendiren 23 araştırmayı incelemişlerdir. Araştırmada ÖG olan öğrencilerin matematik ve bilişsel performansları, gelişimsel yaşları aynı ve daha küçük olan öğrenciler ile karşılaştırarak betimlemişlerdir. Matematik performansı değişkeni açısından bulgular incelendiğinde, ÖG olan öğrencilerin, hesaplama yapma, problem çözme, matematik stratejilerini kullanma ve sayı sayma becerilerinin akranlarına göre daha düşük düzeyde olduğu belirlenmiştir. ÖG olan öğrencilerin çok aşamalı problem çözmede, etkili sayma stratejilerini kullanmada ve matematik probleminde ne sorulduğunu anlamada sınırlılıkları olduğu görülmekle birlikte, işlemleri yaparken belleklerinden bilgileri geri çağırma işlemini otomatik olarak yapamadıkları, olgunlaşmamış stratejileri kullandıkları belirtilmiştir. Bu bulgu bağlamında ÖG olan öğrencilerin, olgunlaşmamış işlem becerileri ve bilgileri zihinden geri çağırma yetersizliklerinden dolayı zihinden işlem yapma becerilerinde kendilerinden gelişimsel yaş olarak daha küçük olan öğrenciler ile karılaştırıldıklarında, bu öğrencilere göre daha düşük performans sergiledikleri görülmektedir. Benzer olarak zorluk derecesi yüksek olan ve yüksek bilişsel performans gerektiren problemlerde de kendilerinden gelişimsel yaş olarak daha küçük olan öğrencilerden daha düşük performans sergiledikleri görülmektedir. Araştırmanın diğer değişkeni olan bilişsel performans (çalışan bellek, işlemleme süresi, uzun süreli bellek, üstbiliş) değişkeni açısından araştırma bulguları incelendiğinde, ÖG olan öğrencilerin sayı ile ilgili becerilerde yürütücü belleklerinde sinırlılıklar olduğu ve görsel uzamsal belleklerinin akranlarına göre anlamlı olarak daha düşük olduğu görülmektedir. Uzun süreli bellek açısından ise ÖG olan öğrencilerin, akranlarına göre bilgileri depolamada ve uzun süreli bellekten bilgileri çağırmada sınırlılıkları olduğu belirtilmektedir. Ayrıca Shin ve Bryant, ÖG olan öğrencilerin bilişsel performans açısından gelişimsel yaşları daha küçük olanlarla karşılaştırdıklarında, anlamlı farklılıklar bulamamışlardır. Bu durum, çalışan bellek ve üstbilişin gelişimsel gecikmeden ve olgunlaşmadan etkilendiği şeklinde yorumlanmıştır. ÖG olan öğrencilerin matematik problemi çözerken yaşadıkları güçlüklerin belirlenmesine ilişkin yapılan araştırma bulguları özetlendiğinde, bu grubun akranlarına göre daha az sıklıkta bilişsel ve üstbilişsel strateji kullandıkları, bunun bilişsel ve üstbilişsel kaynak ile üstbilişsel kontrol sınırlılıklarının bir sonucu olduğu belirtilmektedir (Rosenzweig ve diğ., 2011; Shin ve Bryant, 2015). ÖG olan öğrencilerin kullandıkları stratejilerin belirlenmesi ve bu öğrencilerin güçlü ve zayıf yönlerinin ortaya çıkarılması, öğretim programlarının şekillenmesinde önem arz etmektedir. Her ne kadar yurt dışında yapılan çalışmalarda (Montague ve Applegate, 1993a; Ostad ve Sorenson, 2007; Rosenzweig ve diğ., 2011; Sweeney, 2010) ÖG olan öğrencilerin matematik problem çözmede kullandığı stratejiler incelense de Türkiye'de bu tür çalışmalara rastlanmamıştır. Araştırmacıların bu yönde çalışmalar yapması, ÖG olan öğrencilerin matematik problem çözmede kullandıkları stratejilerin belirlenmesi açısından önemlidir. Bu çalışmada, öğrencilerin problem çözme becerisini gerçekleştirirken kullandıkları stratejileri ortaya koymayı hedefleyen bir değerlendirme çeşidi 
olan, sesli düşünme protokolü tanıtılmış, örneklendirilmiş ve puanlamasının nasıl yapılacağı açıklanmıştır. Ayrıca alanyazında ÖG olan öğrencilerin sesli düşünme protokolü sonuçları tartışlarak, sesli düşünme protokolü ile yapılan değerlendirme sonuçlarının öğretime yansımalarına ilişkin bilgiler verilmiştir. Sonuç bölümünde ise ÖG olan öğrencilerin ve akranlarının kullandıkları bilişsel ve üstbilişsel stratejileri inceleyen araştırmalara duyulan gereksinime değinilerek önerilerde bulunulmuştur. Bu bağlamda, bu çalışmanın araştırmacılara ve öğretmenlere ÖG olan öğrencilerin problem çözmede kullandıkları stratejilerin belirlenmesine yol göstereceği düşünülmektedir.

\section{Sesli Düșünme Protokolleri}

Bilişsel ve üstbilişsel stratejilerin değerlendirilmesinde genellikle sözlü raporlama teknikleri kullanılmaktadır (Desoete ve Roeyers, 2002; Ericson ve Simon, 1984, 1993; Van Hout-Wolters, 2000; Veenman, Kok ve Blöte, 2005). Bu teknikler, yapılan değerlendirme ile incelenen bilişsel ve üstbilişsel boyuta ilişkin sergilenen performansın yerine getirildiği zamana göre sınıflama yapılarak, eş zamanlı, eş zamanlı olmayan (Helms-Lorenz ve Jacobse, 2008) ve her ikisinin bir arada kullanıldığ1 (çok yöntemli düzenlemeler) teknikler olarak üç gruba ayrılmaktadır (Karakelle ve Saraç, 2010). Eş zamanlı olmayan teknikler olarak sıklıkla görüşme ve soru listesi kullanılmaktadır (Chan, 1996; Jacobs ve Paris, 1987; Malpass, O'Neil ve Hocevar, 1999; Minnaert ve Janssen, 1999; Perleth, 1992; Swanson, 1992; Yore ve Craig, 1992). Bu tekniklerin avantaj1, verilerin toplanmasının kolay bir şekilde gerçekleşmesi ve diğer tekniklere göre daha az zaman harcanması olarak belirtilmektedir (Van Hout-Wolters, 2000). Özellikle soru listelerinin bir diğer avantajı ise cevabın tam olarak anlaşılıncaya kadar soruların sorulmaya devam edilebilmesidir (Malpass ve diğ., 1999). Diğer yandan, tekniklerin sağladığı avantajlar kadar dezanavtajlarının da olduğu dikkat çekmektedir. Bu tekniklerin dezavantajı, görüşme ve/veya soru listeleri teknikleri uygulanırken, kişilerin kendi öğrenme aktivitelerine ilişkin birçok ilgili bilgiyi unutmaları, sorulara dikkatlerini yönlendirememeleri ve üzerlerindeki sosyal baskılardan etkilenerek, kişilerin gerçek cevapları verememeleri olarak sıralandığı görülmektedir. Ayrıca soru listeleri tekniğinin ilkokul öğrencilerine uygun olmaması ek bir dezavantaj olarak karşımıza çıkmaktadır (Van Hout-Wolters, 2000). Son olarak, özellikle görüşme tekniğinin hipotetik durumları içermesi, kişilerin kendi yapacağı davranış yerine yapılmasını uygun bulduğu davranışları belirtebilecek olması nedeniyle diğer bir sınırlılık olarak değerlendirilmektedir (Karakelle ve Saraç, 2010). Bilişsel ve üstbilişsel stratejilerin değerlendirilmesinde kullanılan eş zamanlı tekniklerden biri sesli düşünme protokolleridir. Sesli düşünme protokolleri, katılımcıların sözel performansına dayanan, katılımcıların kendilerine verilen bir metin okuma ya da matematik problemi çözme gibi görevler sırasında düşündükleri ve yaptıkları her şeyi sesli olarak belirttikleri bir değerlendirme tekniği olarak tanımlanmaktadır (Montague ve Applegate, 1993b; Ostad ve Sorenson, 2007; Rosenzweig ve diğ., 2011; Swanson, 1990; Sweeney, 2010; Veenman ve Spaans, 2005). Sesli düşünme protokollerinde elde edilen veriler genellikle ses kayıt veya kamera gibi cihazlar ile kayıt edilmekte ve kayıt edilen verilerin dökümü yapılmaktadır (Van HoutWolters, 2000). Yapılan dökümlerde sesletimler, bilişsel ve üstbilişsel stratejiler doğrultusunda incelenerek değerlendirilmektedir (Rosenzweig ve diğ., 2011; Sweeney, 2010). Sesli düşünme protokollerinin, uygulanmasının bir öğrenme aktivitesi (örn, metin okuma ya da matematik problemi çözme gibi) içerisinde gerçekleşmesi sebebi ile katılımcıların zihinsel işlemlerine iliş̧kin ayrıntılı bilgi edinilmesi ve bilginin kayıp olmaması en önemli avantajı olarak belirtilmektedir (Van Hout-Wolters, 2000). Bu noktada, Prins, Veenman ve Elshout (2006), sesli düşünme protokolleri ile veri toplanırken, katılımcılara verilen görevin zorluk seviyesinin ayarlanmasının önemli bir husus olduğunu vurgulamıştır. Bu görüş bağlamında, araştırmalarda yer alan öğrencilerin, sahip olduğu stratejiler değerlendirilirken, kendilerine verilen görevi sesli düşünme kullanmadan otomatik olarak gerçekleşme durumu sınırlılı̆̆ına karşın, sesli düşünme kullanabilecekleri uygun zorluk seviyesinde görevler seçilmesi gerekmektedir (Prins ve diğ., 2006). Sesli düşünme protokollerinin avantajları olduğu gibi dezavantajları da bulunmaktadır. Bu dezavantajların en başında verilerin toplanmasının karmaşık ve zaman alıcı olması gelmektedir (Van Hout-Wolters, 2000). Bu nedenle sesli düşünme protokolleri çoğunlukla geniş gruplara uygulanamamaktadır (Veenman ve diğ., 2005). Diğer bir dezavantaj ise sesli düşünme protokollerinin, kişinin bir görevi yerine getirirken, eş zamanlı olarak düşündüklerini ve yaptıklarını anlatıyor olmasının sürecin yapısını olumsuz olarak etkileyeceğidir (Baker ve Cerro, 2002; Paris ve Flukes, 2005). Sözel olarak ifade edilen işlemler, kişinin zihinsel süreçlerini tam olarak yansıtıp yansıtmadığı, herhangi bir bilişsel işlem 
bilgisinin atlanıp atlanmadığı ve düşünülenler ile söylenenler arasında kayıp veri olup olmadığı gibi faktörlerin veri toplama sürecini olumsuz olarak etkilediği düşünülmektedir (Van Hout-Wolters, 2000). Ancak bu durumun dezavantaj olduğu görüşünün aksine, Veenman ve diğerleri, (2005), sesli olarak düşünmenin veri toplama sürecini olumsuz olarak etkilemeyeceğini belirtmişlerdir. Belirtilen eleştiri kişinin zihninden geçen her şeyi söylediği veya söyleyeceği varsayımına dayalıdır. Bu bağlamda, Ericson ve Simon (1993), belirtilen sınırlılığı bellek kuramı ile açıklamaya çalışarak, kısa süreli belleğin ya da algısal kayıt alanının sadece uyanık/bilinçli kısmının sesletimler şeklinde dökülebildiğini belirtmişlerdir. Uzun süreli bellekte olan bilgilerin ise doğrudan sözcüklere/sesletimlere dökülemediğini, önce uzun süreli bellekten çağrılıp, kısa süreli bellek bilgileri ile ilişkilendirildiğini ileri sürmüşlerdir. Dolayısı ile sesli düşünme bilişin uyanık/bilinçli kısımda gerçekleştiği için bilişsel ve üstbilişsel sürece engel olmadığını belirtmektedir (Ericson ve Simon, 1993).

Alanyazında bilişsel ve üstbilişsel stratejilerin değerlendirilmesinde kullanılan eş zamanlı olan ve eş zamanlı olmayan tekniklerin birbirleri ile karşılaştırılmasına, aralarındaki ilişkiyi ölçümlemeye yönelik araştırmalar yapıldığı görülmektedir (Van Hout-Wolters, 2000). Sesli düşünme protokolleri ile yapılan ölçümlerin diğer eş zamanlı olan teknikler (örn, bilgisayar destekli ölçümler) ile yüksek derecede ilişkili olduğu bulunmuştur (Van Hout-Wolters, 2000; Veenman ve diğ., 2005). Eş zamanlı olan teknikler ile olmayan teknikler karşılaştırıldığında ise aralarındaki ilişkinin oldukça düşük olduğu belirtilmiştir (Van Hout-Wolters, 2000). Bu bulgular ışığında, eş zamanlı olmayan teknikler aracılığı ile yapılan ölçümlerin, eş zamanlı olanlara göre ölçülen değişkene ilişkin daha zayıf bilgi verdiği belirtilmektedir (Van Hout-Wolters, 2000; Veenman ve diğ., 2005). Tekniklerin güçlü yanlarından daha fazla yararlanmak, zayıf yanlarına ilişkin sınırlılıklarından daha az etkilenmek amaciyla, son yıllarda eş zamanlı olan ve olmayan tekniklerin bir arada ya da belirtilen tekniklerin birden fazla sayıda aynı araştırmada kullanılmasının gerekliliğinden söz edilmektedir (Desoete, Roeyers ve Buysse, 2001; Karakelle ve Saraç, 2010; Veenman ve Spaans 2005).

Son yıllarda sesli düşünme protokolleri kullanılarak yapılan araştırma sayılarının artması (Ostad ve Sorenson, 2007; Rosenzweig ve diğ., 2011; Sweeney, 2010), bilişsel ve üstbilişsel stratejilerin değerlendirilmesinde sıklıkla kullanılan bir teknik olarak belirtilmesi (Pressley ve Afflerbach, 1995) ve diğer eş zamanlı tekniklerle yüksek derecede ilişkili olduğunun vurgulanması (Van Hout-Wolters, 2000), bu tekniğinin sınırlılıkları ile birlikte kullanılabileceği ve bilişsel ve üstbilişsel stratejilere ilişkin değerli bilgiler elde edilebildiğini göstermektedir (Montague ve Applegate, 1993b; Sweeney, 2010).

\section{Sesli Düşünme Protokollerinin Uygulanması}

Sesli düşünme protokolleri bir metin okuma ya da matematik problemi çözme gibi akademik etkinlikler sırasında kullanılabilmektedir (Pressley ve Afflerbach, 1995; Rosenzweig ve diğ., 2011). Bu çalışmada ise matematik problemi çözme sırasında sesli düşünme protokollerinin uygulanmasına yer verilmiştir.

Sesli düşünme protokolleri iki aşamada uygulanmaktadır. İlk aşamada sesli düşünme eğitimi yapılmakta, ikinci aşamada ise uygulaması yapılmaktadır (Montague ve Applegate, 1993b; Ostad ve Sorenson, 2007; Rosenzweig ve diğ., 2011; Sweeney, 2010). Sesli düşünme eğitim süreci öğrenci ile bireysel olarak üç aşamada gerçekleştirilmektedir (Sweeney, 2010). İlk olarak, uygulamacı çalışmanın amacını açıklayarak, sesli düşünme tekniğinin, öğrencilerin matematik problemini nasıl çözdüklerini anlamada neden iyi bir yol olduğuna ilişkin ögrenciye bilgi verir (Sweeney, 2010). Bu noktada, uygulamac1, 'Ben senin matematik problemlerini nasıl çözdügüü ile ilgileniyorum, bu nedenle sana çözmen için matematik problemi vereceğim ve senin bu soruları nasıl çözdüğünü dinleyeceğim. Bu süreçte ben problemin sonucu ile değil, senin problem hakkında nasıl düşündüğün ile ilgileneceğim. Sana verilen matematik problemlerini çözerken neler söylediğin benim için çok önemli, bu nedenle söylediğin hiçbir şeyi unutmadığımdan emin olmak için bu kayıt cihazını kullanacağım' şeklinde sesli düşünme protokolünün nasıl yapılacağını öğrenciye açıklar (Johnstone, Bottsford-Miller ve Thompson, 2006). Belirtilen girişin ardından ikinci olarak, uygulamacı bir matematik problemi üzerinde sesli düşünme sürecine model olur. Bu süreçte uygulamacı, matematik problemi üzerinden kendini sorgulama, kendini talimatlandırma ve kendini izleme gibi davranışlar sergileyerek sesli olarak düşünür (Rosenzweig ve diğ., 2011). Son olarak, 
uygulamacı öğrenciye uygulamacının kullandığı problemden farklı olan bir matematik problemi vererek, öğrencinin bu problemleri sesli düşünerek çözmesini ister. İkinci bir problem için de süreci tekrar eder. Uygulamacı, matematik problemi çözme sırasında öğrencinin ses tonunun uygunluğunu ve anlaşılırlığını destekleyerek, sesli düşünme protokolünün eğitimi kısmını tamamlar (Montague ve Applegate, 1993b). Üç aşamada uygulanan sesli düşünme protokolü eğitiminde, matematik problemi çözme sırasında öğrencinin 5 sn süreden daha fazla sessiz kalması durumunda, uygulamacı öğrencinin düşündükleri, hissettikleri ve yaptıkları her şeyi söylemeleri gerektiğini öğrenciye hatırlatmalıdır (Montague ve Applegate, 1993b; Ostad ve Sorenson, 2007; Rosenzweig ve diğ., 2011; Sweeney, 2010).

Sesli düşünme protokolü eğitimi aşamasından sonra uygulama aşamasına geçilir ve eğitim aşamasında olduğu gibi öğrenci ile bireysel olarak uygulama yapılır (Montague ve Applegate, 1993b; Ostad ve Sorenson, 2007). Uygulamac1, bu aşamada da sesli düşünme protokolü eğitiminde verdiği yönergeyi tekrar ederek uygulamaya başlar (Johnstone, Bottsford-Miller ve Thompson, 2006). Uygulamacı öğrenciye 'sesli düşünmeyi gerçekleştirirken, matematik problemini sıra ile çözeceksin ve her problemi çözerken zihninde yapmak istediklerini, düşündüklerini ve ne hissettiğini söyleyeceksin' der. Daha sonra uygulamacı, 'Matematik problemlerini sesli düşünerek çözerken, doğal olmanı istiyorum' diyerek öğrenciyi rahatlatmaya yönelik ifadeler kullanır. Uygulamac1, öğrencinin sesli düşünmeyi unuttuğu zamanlarda, "Lütfen sesli düşünmeyi unutma" şeklinde öğrencinin düşündükleri, hissettikleri ve yaptıkları her şeyi söylemeleri gerektiğini hatırlatmak amacıyla uyarılarda bulunabileceğini belirtir (Sweeney, 2010).

Uygulamac1, öğrenciye çözeceği problemi vererek, 'Problemi çözmeye hazır mısın?' diye sorar. Öğrenciden hazırım cevabını aldıktan sonra 'Şimdi problemi sesli düşünerek çözmeni istiyorum' diyerek uygulamayı başlatır. Öğrenci problemi çözerken yanlış yaptığı işlemlere veya öğrencinin zorlandığı işlemlere yönelik olarak hiçbir müdahalede bulunulmaz. Ancak öğrenci sesli düşünmeyi $5 \mathrm{sn}$ süresince gerçekleştirmediği durumlarda 'Lütfen sesli düşünmeyi unutma' şeklinde hatırlatmalarda bulunulur. Ek olarak, duraksadığı zamanlarda 'Şu anda ne düşünüyorsun? Aferin işlemleri çok güzel yapıyorsun. Çok güzel sesli düşünmeye devam et.' gibi öğrencinin sesli düşünmesini devam ettirmesini teşvik edecek ifadeler kullanır. Uygulama toplam üç farklı zorluk düzeyinde olan problemler için benzer şekilde uygulanır (Montague ve Applegate, 1993b; Ostad ve Sorenson, 2007; Rosenzweig ve dĭ̆., 2011; Sweeney, 2010).

Araştırmalarda sesli düşünme protokollerinde kullanılan matematik problemleri, problemin çözülmesi için yapılması gereken işlem sayısını ve problemin zorluğunu belirtmek amacıyla bir, iki ve üç aşamalı problemler olarak tanımlanmıştır (Rosenzweig ve diğ., 2011; Sweeney, 2010). Bu bağlamda sesli düşünme protokolünün uygulamasında üç problem kullanılır. Bir aşamalı problem, bir işlem yapılarak problemin çözüldüğü kolay problemi, iki aşamalı problem, iki işlem yapılarak problemin çözüldüğü orta zorluk düzeyinde olan problemi, üç aşamalı problem ise üç işlem yapılarak problemin çözüldüğü zor olan problemi belirtir (Rosenzweig ve diğ., 2011; Sweeney, 2010). Üç farklı zorluk düzeyinde (kolay/orta/zor) problem hazırlanmasının amacı, problemlerin zorluk düzeyleri ile öğrencilerin yaptıkları sesletimler ile kullandıkları stratejilerin farklılaşma durumunu belirlemektir (Sweeney, 2010).

\section{Sesli Düşünme Protokollerinin Puanlanması}

Sesli düşünme protokollerinin puanlanmasında, sesli düşünme protokolü uygulama sırasında, kayıt cihazı ile kayıt edilen sözel veriler, öğrenci ile görüşmenin tamamlanmasının ardından, üzerlerinde hiçbir düzeltme yapılmadan, öğrenci tarafından ifade edilenlerin aynen duyulduğu şekilde dökümü yapılır (Sweeney, 2010). Bilişsel sesletimlerin, üretici olan üstbilişsel sesletimlerin ve üretici olmayan üstbilişsel sesletimlerin ayrı problem için sıklıkları hesaplanır (Montague ve Applegate, 1993b; Ostad ve Sorenson, 2007; Rosenzweig ve diğ., 2011; Sweeney, 2010). Bilişsel olan sesletimler, problemin okunması, öğrencinin problemi kendi cümleleri ile ifade etmesi, problemin çözümünde görselleştirme ögelerini kullanması, hipotez oluşturması, tahminde bulunması, hesaplama yapması ve kontrol etmesini kapsar (Rosenzweig ve diğ., 2011). Üretici olan üstbilişsel sesletimler; problem çözümüne ilişkin kendini izleme, kendini talimatlandırma ve kendini sorgulama ifadelerini içerir (örn, 
'Problemi tekrar okumaya ihtiyacım var.', 'Şu anda ne yapıyorum.' vb.). Üretici olmayan sesletimler ise duygu durumunu içeren ifadeleri kapsar (örn, 'Kafam karıştı.', 'Ne yapacağımı bilmiyorum.' vb.). Öğrencinin sesli düşünme protokolü sırasında ortaya çıkan sesletimleri nitel olarak analiz edildikten sonra (bkz. Ek A1, A2, A3) sesli düşünme protokolü kodlama formuna (bkz. Ek B) öğrencinin kullandığı bilişsel ve üstbilişsel sesletimler sıklık ve yüzde olarak kayıt edilir. Böylece nitel veriler nicel veriye dönüştürülür.

Altıncı sınıfa devam eden normal gelişim gösteren, öğrenme güçlüğü ve üstün yetenekli olan üç öğrencinin zor düzeyde olan matematik problemi çözme sırasında sesli düşünme protokolü ile elde edilen sesletimlerinin analiz örneği Ek A1, A2, A3'de, sesli düşünme protokolü örnek kodlama formu ise Ek B'de yer almaktadir.

\section{Sesli Düşünme Protokolü Güvenirlik Hesaplamaları}

Sesli düşünme protokolü uygulamalarında, uygulama güvenirliği ve kodlamacılar arası güvenirlik olmak üzere iki farklı güvenirlik hesaplaması yapılmaktadır (Sweeney, 2010). Uygulama güvenirliği sesli düşünme protokolü eğitimi ve uygulaması aşamaları için hesaplanmaktadır. Uygulama güvenirliği formu sesli düşünme protokolü eğitimi ve uygulanması oturumlarının her bir aşaması için hazırlanır. Uygulama güvenirliği formu araştırma süresince takip edilen sesli düşünme eğitim ve uygulama oturumlarının adımlarını içerecek şekilde listelenir ve bir kontrol listesi hazırlanarak gözlemciye verilir. Gözlemcinin güvenirlik formlarının nasıl kullanılacağı konusunda bilgilendirilmesinin ardından, uygulama esnasında gözlemcinin öğrencinin dikkatini çekmeyecek ve uygulamayı izleyecek bir yere oturması sağlanır ve uygulamacıyı izlemesi, uygulamada aksayan ya da yanlış giden noktalarda araştırmacıyı bilgilendirmesi istenir. Araştırmalarda veri toplanmaya başlanmadan önce pilot uygulamalar sırasında gözlemci, uygulama ortamında doğrudan gözlemler yapmalıdır. Yüzde 90 ve üzeri güvenirlik sağlandıktan sonra izleme sonlandırılır. Ayrıca veri toplama süreci bitiminde sesli düşünme protokolü eğitimi ve uygulanması oturumlarının en az \%30’unu karşılayacak şekilde uygulama güvenirliğinin hesaplanmalıdır. Uygulama güvenirliği gözlenen araştırmacı davranışının planlanan araştırmacı davranışına bölünerek yüzdesinin alınması yolu ile hesaplanır (Billingsley, White ve Munson, 1980).

Araştırmada sesli düşünme protokolünün uygulanması sonucu elde edilen verilerin en az \%30’u için kodlamacılar arası güvenirlik hesaplanır. Kodlamacı, hem öğrencilerin problem çözme süreçlerini içeren sesletimlerin doğru olarak dökümünün yapılma durumunu hem de öğrencilerin problem çözme sürecinde kullandıkları bilişsel ve üstbilişsel stratejilerin doğru olarak belirlenme durumunu inceler (Sweeney, 2010). Her iki durum için, kodlamacılar arası güvenirlik hesaplamasında 'görüş birliği / (görüş birliği+görüş ayrılığ 1 ) X 100' formülü kullanılarak kodlamacılar arası güvenirlik hesaplanır (House, House ve Campbell, 1981). Belirtilen sesli düşünme protokolü süreci Tablo 1'de özetlenmiştir.

\section{ÖG Olan Öğrencilerde Matematik Problemi Çözmede Uygulanan Sesli Düşünme Protokollerinin Sonuçları}

Alanyazında üstbilişin matematik problemi çözmede önemli bir rolü olduğu vurgulanmaktadır. Bu bağlamda Swanson (1990) sesli düşünme protokülü kullanarak, farklı başarı ve üstbiliş düzeyinde olan öğrencilerle yaptığı bir çalışmayla önemli bulgulara ulaşmıştır. Swanson, dördüncü ve beşinci sınıflara devam eden 56 öğrencinin strateji kullanımlarını ve problem çözüm süreçlerini belirlemiştir. Çalışma grubunda yer alan öğrenciler, yüksek başarıl1-yüksek üstbiliş, yüksek başarılı-düşük üstbiliş, düşük başarıl1-yüksek üstbiliş ve düşük başarılı-düşük üstbiliş düzeyi olarak dört gruba ayrılmıştır. Gruplardan kendilerine verilen problemleri sesli düşünerek çözmeleri istenmiştir. Araştırma bulguları incelendiğinde, başarı düzeylerine bakılmaksızın, yüksek üstbilişsel düzeyde olan öğrencilerin düşük üstbilişsel düzeyde olan akranlarına göre daha fazla strateji kullanımı sergiledikleri belirlenmiştir. Buna karşın, düşük başarılı-yüksek üstbiliş düzeyinde olan grup, yüksek başarıl1düşük üstbiliş düzeyinde olan gruba göre anlamlı olarak daha iyi performans sergiledikleri görülmekle birlikte yüksek başarılı-yüksek üstbiliş düzeyinde olan grubun diğer üç gruba göre daha fazla strateji kullandıkları bulunmuştur. Araştırmacı, bulguların üstbilişin genel başarı düzeyi ile ilişkili olabileceğini ancak genel başarı düzeyinden bağımsız bir yapı olarak ele alınması gerektiğini belirtmiştir. Diğer bir deyişle, öğrencilerin ön bilgisi ya da zekâ düzeyleri ne olursa olsun üstbilişsel olarak daha iyi durumda olan öğrencilerin problemleri daha etkin 
bir biçimde çözdükleri sonucuna varılmıştır.

Tablo 1

Sesli Düşünme Protokolü Uygulama Süreci

\begin{tabular}{|c|c|c|}
\hline İşlem Sırası & İşlem & İşlem Süreci \\
\hline 1 & $\begin{array}{l}\text { Sesli Düşünme } \\
\text { Protokolü Eğitimi }\end{array}$ & $\begin{array}{c}\text { Çalışmanın amacının açıklanması ve Johnstone ve diğerleri (2006)'dan } \\
\text { uyarlanan yönergenin okunması } \\
\text { Sesli düşünme protokolü sürecine bir problem üzerinden model olunmas1 } \\
\text { Öğrencinin iki farklı problemlemi sesli düşünerek çözmesi }\end{array}$ \\
\hline 2 & $\begin{array}{l}\text { Sesli Düşünme } \\
\text { Protokolü Uygulaması }\end{array}$ & $\begin{array}{c}\text { Johnstone ve diğerleri (2006)'dan uyarlanan yönergenin okunması } \\
\text { Kolay problemin çözülmesi } \\
\text { Orta zorluk düzeyinde olan problemin çözülmesi } \\
\text { Zor problemin çözülmesi }\end{array}$ \\
\hline 3 & $\begin{array}{l}\text { Sesli Düşünme } \\
\text { Protokolü Puanlanması }\end{array}$ & $\begin{array}{c}\text { Sesletimleri nitel olarak analiz edilmesi } \\
\text { Nitel verilerin nicel verilere dönüştürülmesi } \\
\text { Öğrencinin kullandığı bilişsel ve üstbilişsel sesletimlerin sıklık ve yüzde } \\
\text { olarak sesli düşünme protokolü kodlama formuna kayıt edilmesi }\end{array}$ \\
\hline 4 & $\begin{array}{l}\text { Sesli Düşünme } \\
\text { Protokolü Güvenirlik } \\
\text { Hesaplamaları }\end{array}$ & $\begin{array}{l}\text { Uygulama güvenirliğin hesaplanması } \\
\text { Kodlamacılar arası güvenirliğin hesaplanması }\end{array}$ \\
\hline
\end{tabular}

Alanyazında birçok çalışmada ÖG olan öğrencilerin matematik problemi çözmede kullandıkları bilişsel ve üstbilişsel stratejileri sesli düşünme protokolleri kullanılarak incelenmiştir (Montague ve Applegate, 1993b; Ostad ve Sorenson, 2007; Rosenzweig ve diğ., 2011; Swanson, 1990; Sweeney, 2010). Montague ve Applegate (1993b), ortaokul altıncı, yedinci ve sekizinci sınıflara devam eden, ÖG olan öğrenciler ile ortalama başarılı ve üstün yetenekli öğrencilerin matematik problemi çözmede kullandıkları bilişsel ve üstbilişsel stratejilerini incelemeyi amaçlamışlardır. Araştırma bulguları incelendiğinde, ÖG olan ve ortalama başarılı öğrencilerin, üstün yetenekli öğrencilere göre daha az bilişsel ve üstbilişsel sesletim yaptıkları bulunmuştur. Bir aşamalı problemlerde çalışma grubunu oluşturan öğrenci grupları arasında sesletim farklılıkları anlamlı bulunmamıştır. Bu bulgu, bir aşamalı problemin diğer problemlere görece basit olmasından dolayı ortalama başarılı ve üstün yetenekli öğrencilerde problem çözerken bilişsel ve üstbilişsel stratejilerde otomatikleşme sağladiğ 1 yönünde yorumlanmıştır. İki aşamalı problemlerde, üstün yetenekli öğrencilerin ÖG olan öğrencilere göre daha fazla bilişsel ve üstbilişsel sesletim yaptıkları bulunmuştur. Üç aşamalı problemlemlerde ise üstün yetenekli ve ortalama başarılı öğrenciler, ÖG olan öğrencilere göre daha fazla bilişsel ve üstbilişsel sesletim yapmışlardır. ÖG olan öğrencilerin üç aşamalı problemde bilişsel düzeylerini son noktada zorladıkları ancak sesletim süreçlerine ilişkin yeteneklerini problemin zor olması nedeniyle kapattıkları vurgulanmıştır. Üç aşamalı probleme ilişkin elde edilen bulgular, zorluk düzeyi yüksek olan problemlerde üstün yetenekli olan öğrencilerin üstbilişsel stratejileri kullanmaya başladıklarını göstermiştir. Katılımcıların sınıf düzeyi çeşitliliği bakımından dikkat çeken diğer bir araştırmada, Ostad ve Sorenson (2007), ikinci sınıftan yedinci sınıfa kadar ÖG olan ve olmayan 134 öğrencinin matematik problemi çözme sırasındaki strateji kullanımlarını incelemişlerdir. Araştırma bulguları incelendiğinde, çalışma grubunda yer alan öğrencilerin görevle ilişkili konuşmaların üstbilişleri ile pozitif yönde ilişkili olduğu bulunmuştur. Aynı zamanda, ÖG olan öğrencilerin ÖG olmayan öğrencilere göre daha fazla destekleyici stratejiler kullandıkları (örn, parmak ile sayma), ÖG olmayan öğrencilerin ise ÖG olan öğrencilere göre daha fazla zihinlerinden geri çağırma stratejilerini kullandıkları görülmüştür. Araştırmacılar, bu bulguların öğrencilerin üstbilişsel stratejileri olmaması ile ilişkili değil, olgunlaşmaması ile ilişkili olabileceğini vurgulamışlardır. Bilişsel ve üstbilişsel stratejilerilerin değerlendirilmesinde çoklu düzenlemelerin, diğer bir deyişle eş zamanlı ve eş zamanlı olmayan ölçümlerin bir arada kullanılması ile dikkat çeken araştırmada Sweeney (2010), ÖG olan öğrenciler ile düşük ve ortalama başarılı öğrencilerin matematik problemi çözmede kullandıkları üstbilişsel stratejilerilerini incelemiştir. Araştırmanın çalışma grubunu; 15 ÖG, 38 düşük başarılı ve 29 ortalama başarılı olmak üzere toplam 82 öğrenci oluşturmuştur. Araştırmada, öğrencilerin matematik problemi çözmede kullandıkları üstbilişsel stratejileri değerlendirmek amacıyla sesli düşünme protokolleri kullanılmıştır. Araştırma bulguları incelendiğinde, 
ÖG olan öğrencilerin üretici olan ve olmayan üstbilişsel sesletimleri arasındaki farklılık anlamlı bulunmuştur. Bu bulgu, öğrencilerin problemi çözmek için gerekli stratejilerden yoksun oldukları ve problem çözme sürecinde sahip oldukları stratejileri uygulayamadıkları şeklinde yorumlanmıştır. Ek olarak, öğrencilerin üç aşamalı problemin kendi problem çözme yeteneklerini aştığını düşünmeleri ve bu nedenle problem çözmeyi bıraktıkları belirtilmiştir. Sesli düşünme protokollerinin son yıllarda kullanıldığ 1 diğer bir araştırmada ise Rosenzweig ve diğerleri (2011) sekizinci sınıfa devam eden ÖG olan öğrenciler ile düşük ve ortalama başarılı öğrencilerin matematik problemi çözmede kullandıkları üstbilişsel stratejileri arasındaki farklılıklığı belirlemişlerdir. Araştımanın çalışma grubunu ÖG olan 14, düşük başarılı 34 ve ortalama başarılı 25 olmak üzere toplam 73 öğrenci oluşturmuştur. Araştırma bulguları incelendiğinde araştırmada üç anlamlı ilişki bulunmuştur. İlk olarak, yetenek grupları ile problemlerin zorluk seviyeleri aralarındaki ilişkinin anlamlı olduğu, bu bağlamda, düşük başarılı olan öğrencilerin iki aşamalı problemlerde bir aşamalı problemlere göre daha az üstbilişsel sesletim yaptıkları bulunmuştur. İkinci olarak, üstbilişsel sesletim türleri ile problemin zorluk seviyeleri arasındaki ilişkinin anlamlı olduğu, problemlerin zorluk düzeyleri arttıkça, üretici olmayan sesletim sayıların arttığı gözlenmiştir. Son olarak, yetenek grupları, problem zorlukları ve üstbilişsel sesletim türleri arasında anlamlı ilişki olduğu bulunmuştur. Araştırmada kullanılan problemler zorlaştıkça, gruplar arasında üstbilişsel sesletim türleri farklılaşmıştır. ÖG olan öğrenciler ile ortalama başarılı öğrenciler üretici olmayan üstbilişsel sesletimlerini bir aşamalı problemlerden üç aşamalı problemlere doğru artırmışlardır. Düşük başarılı öğrenciler ise bir aşamalı problemlerde iki aşamalı problemlere göre daha düşük, iki aşamalı problemlerde ise üç aşamalı problemlere göre daha yüksek üretici olmayan üstbilişsel sesletimler kullanmışlardır. Araştırma bulguları tartışılırken, özellikle ÖG olan ve düşük başarılı öğrencilerin üç aşamalı problemlerde daha fazla üretici olmayan üstbilişsel sesletim yapmaları, öğrencilerin zor bir problem ile karşılaştıklarında problemi çözmek için uygun kaynaklara sahip olamamalarına veya uygun kaynakları kullanamamalarına dayandırılmıştır. Bu doğrultuda, araştırma bulguları incelendiğinde, tüm öğrencilerin üretici olmayan üstbilişsel sesletimleri problemlerin zorluk seviyeleri ile doğru orantılı olarak artmış, buna karşın ortalama başarılı öğrencilerin üretici olan sesletimlerinde problemlerin zorluk seviyeleri ile doğru orantılı olarak artış olduğu vurgulanmıştır. Ek olarak, ÖG olan öğrencilerin başlangıçta bir aşamalı problemden iki aşamalı probleme geçişte üretici olan üstbilişsel sesletimlerini artırdığı ancak üç aşamalı problemde bu artışın olmadığ 1 belirlenmiştir. Bu durumun ise diğer araştırmalarda olduğu gibi (Montague ve Applegate, 1993b; Sweeney, 2010) ÖG olan öğrencilerin, problemin çözülmesinin çok zor olduğunu düşünme algılarından dolayı hemen düşünme yollarını kapatmalarından ve üstbilişsel kaynaklarını tükenmiş olarak algılamalarından kaynaklandığı ileri sürülmüştür.

ÖG olan öğrencilerin ve akranlarının matematik problemi çözerken kullandıkları bilişsel ve üstbilişsel stratejilerinin belirlenmesine ilişkin yapılan araştırma bulguları özetlendiğinde, öğrencilerin görevle ilişkili sesletimlerinin üstbilişleri ile pozitif yönde ilişkili olduğu, bu bağlamda yüksek üstbilişsel düzeyde olan öğrencilerin düşük üstbilişsel düzeyde olanlara göre daha fazla bilişsel ve üstbilişsel strateji kullanımı sergiledikleri, ÖG olan öğrenciler ve ortalama başarılı öğrencilerin, üstün yetenekli öğrencilere göre daha az strateji sesletimi yaptıkları bulunmuştur. ÖG olan öğrenciler, ortalama başarılı olan akranları ile karşılaştırıldığında, ÖG olan öğrencilerin sınırlı üstbilişsel kaynaklara sahip oldukları belirtilmekte, üstbilişsel strateji kullanımlarının ortalama başarılı olan akranlarına göre sınırlı olduğu görülmektedir. Ek olarak, problemin zorluk derecesi arttıkça, ÖG olan öğrenciler daha fazla üretici olmayan üstbilişsel strateji kullanımı eğiliminde oldukları ve üretici üstbilişsel stratejilerini harekete geçiremedikleri belirtilmiştir. Sonuç olarak, ÖG olan öğrencilerin bilişsel ve üstbilişsel strateji kullanımında gösterdikleri sınırlıklar üç temel çerçevede tartışılmıştır. Bunlardan birincisi ÖG olan öğrencilerin strateji kullanımların geç olgunlaşması (Ostad ve Sorenson, 2007) ikincisi üstbilişsel ve bilişsel stratejilerinde yetersizliklerinin olması (Montegaue ve Applegate, 1993b; Sweeney, 2010) üçüncü olarak da sahip oldukları stratejileri etkili ve verimli şekilde kullanmamalarıdır (Sweeney, 2010). Bu noktada, araştırmacılar yüksek düzeyde düşünme becerileri gerektiren görevlerde öğrencilerin başarılı olmalarına yardımcı olabilmek amacıyla, özellikle ÖG olan öğrencilere bilişsel ve üstbilişsel stratejilerin öğretiminin yapılmasının önemli olduğunu belirtmişlerdir (Montague ve Applegate, 1993b; Ostad ve Sorenson, 2007; Rosenzweig ve diğ., 2011; Swanson, 1990; Sweeney, 2010). 


\section{Sesli Düşünme Protokolleri Değerlendirme Sonuçlarının Öğretime Yansımaları}

Sesli düşünme protolleri sonucunda elde edilen veriler kâğıt-kalem testleri ile elde edilemeyen, ulaşılması güç olan bilgileri uygulamacılara sağlamaktadır (Sweeney, 2010). Bu bilgilerle uygulamacılar, öğrencilerin yönetici becerileri, problem çözüm sürecinde kullandıkları stratejileri ve yaptıkları farklı hata türleri gibi özel alanlarda bilgi sahibi olabilmektedir (Rosenzweig ve diğ., 2011). Bu doğrultuda, sesli düşünme protokolleri sonucunda elde edilen veriler, öğrenci profillerinin belirlenmesinde, betimlenmesinde ve bu öğrencilerin gereksinimlerine yönelik uygun öğretim programlarının olușturulmasında kullanılabilmektedir. Örneğin, üstbilişsel stratejilere sahip olan ancak bilişsel sınırlılığ 1 nedeni ile uygun şekilde üstbilişsel stratejilerini kullanamayan öğrenciler için strateji odaklı programlara ihtiyaç duyulmaktadır. Bu öğrenciler için gereksinimleri doğrultusunda bilişsel ve üstbilişsel stratejileri içeren öğretim programları hazırlanabilmektedir (Montague, 1992). Üstbilişsel stratejilerin problem çözme sürecinde faydalı olabilmesi için gelişimsel olarak uygun bilişsel stratejiler ile ilişkili olması gerekmektedir. Nitekim Montague (1992) tarafından geliştirilen Bunu Çöz (Solve it!) strateji öğretim programı, ÖG olan öğrencilerin problem çözme sınırlıklarının üstesinden gelinmesinde bilişsel ve üstbilişsel stratejilerin birlikte kullanıldığı etkili bir model olarak alanyazında yer almaktadır. Bunu Çöz; okuma, kendi cümleleri ile ifade etme, görselleştirme, hipotez oluşturma, tahmin etme, hesaplama, kontrol etme bilişsel stratejileri ile söyleme, sorgulama ve kontrol etme üstbilişsel stratejilerin kullanıldığı bölümlerden oluşmakta ve bilişsel ile üstbilişsel rutinleri içermektedir. Bu model ile öğrencilere ne yapacaklarını kendilerine nasıl söyleyecekleri, kendilerini sorgulama ve problem çözme sürecinde kendilerini kontrol etme/izleme öğretilmektedir (Sweeney, 2010).

Bilişsel strateji öğretimi ile öğrencilere söz konusu akademik beceriyi yerine getirmeleri için gerekli olan stratejilerin nasıl uygulandığının öğretilmesi hedeflenmektedir (Özmen, 2017). Aynı zamanda üstbilişsel strateji öğretimi ile de öğrencilerin öğrenme sürecinde aktif katılımcılar olmaları ve tıpkı usta problem çözücüler gibi zor becerilerle karşılaş̧ıklarında uygun bilişsel süreçlerine rehberlik edecek üstbilişsel statejiler öğretilebilmektedir (Sweeney, 2010). Böylece öğrencilerin zor ve yeni bir görevle karşılaştıklarında uygun stratejileri seçmelerine ve uygulamalarına yardımcı olmanın yanı sıra üstbilişsel farkındalıkları da artırmaktadır (Sweeney, 2010). Başarılı bir şekilde problem çözümü için gerekli olan bilişsel becerilerin yokluğunda, öğrencilerin üstbilişsel becerilerine güvenmek durumunda kaldıkları belirtilmektedir (Veenman ve Spaans, 2005). Üstbilişsel strateji öğretimi ile başarılı bir şekilde problem çözme için gerekli olan strateji farkındalığını artırılması ve öğrencilerin bu stratejileri içselleştirilmesi sonucu öğrencilerin bilişsel yükleme alanları azaltılarak çalışan belleklerinde boşluk oluşturma/otomatikleşme sağlanmaktadır (Sweeney, 2010).

Usta problem çözücüler genellikle problem çözümü için gerekli olan bilişsel becerilere sahiptirler ve problem zor olmadığı sürece üstbilişsel becerilerini aktif hale getirmeye gereksinim duymazlar (Crowley, Shrager ve Siegler, 1997). Üstbilişsel stratejilerin bilinçli ve amaçlı olarak kullanımı öğrencilerin problem çözme sürecini içselleştirerek, bilişsel stratejilerini uygulamalarına yardım etmektedir. Usta problem çözücüler matematik problemi çözmek için kendi üstbilişsel stratejilerini etkinleştirmeye gereksinim duymadıklarından dolayı problem çözümünde ustalaşmamış kişilere göre daha az üstbilişsel sesletimler yapmaktadırlar. Bu bağlamda, sesli düşünme protokolleri sonucunda elde edilen veriler aracılığı ile öğrencilerin bilişsel ve üstbilişsel strateji kullanımları belirlenebilmekte ve kullanımında sinılılıkları olan stratejilere yönelik strateji öğretim programları geliștirilebilmektedir. Diğer yandan sesli düşünme protokolleri aracıllığ ile elde edilen verilerde uygun olan strateji kullanımları görülebilmekte, bu doğrultuda öğrencilerin uygun olarak kullandıkları bilişsel ve üstbilişsel stratejilerinin diğer akademik alanlara da genellenmesi hedeflenebilmektedir (Rosenzweig ve diğ., 2011).

\section{Sonuç}

Flavell'in üstbiliş terimini ortaya atmasından bu yana üstbiliş alanında yapılan araştırmalar hızla artmıştır. Uluslararası alanyazında üstbiliş ile ilgili araştırmalar 1978'li yıllardan bu yana yapılırken (Brown, Campione ve Day, 1981; Kluwe, 1982), Türkiye'de bu alandaki araştırmaların 1990'lı yıllardan itibaren yapılmaya başlandığı belirtilmektedir (Doğan, 2013). Türkiye'de yapılan araştırmalar incelendiğinde, araştırmaların çoğunlukla normal 
gelişim gösterenler ile yürütüldüğ̈̈, konularının ise dil öğretimi (Muhtar, 2006; Tunçman, 1994; Yüzbaşığlu, 1991), matematik öğretimi (Demir-Gülşen, 2000; Ekenel, 2005; Küçük-Özcan, 2000; Pilten, 2008), öğretmen eğitimi (Özcan, 2007; Yavuz, 2009) bilgisayar öğretimi (Akdur, 1996), okuduğunu ve dinlediğini anlama (Çakıroğlu,2007; Çiçekçioğlu, 2003; Gelen, 2003), ölçek geliştirme (Karakelle ve Saraç, 2007; Namlu, 2004), problem çözme (Özsoy, 2007) ile ilgili olduğu görülmektedir. Dolayısıyla, değişkenler çeşitli olmakla birlikte, sadece normal gelişim gösteren öğrencilerde üstbilişin incelendiği görülmektedir. Özel gereksinimli çocuklarda ise alanyazın oldukça sınırlıdır. Özel eğitim alanı ile ilişkili olarak, ülkemizde üstbilişsel veya bilişsel strateji çalışmalarının zihinsel yetersizlikten etkilenmiş öğrenciler ile sınırlı olduğu (Doğanay-Bilgi ve Özmen, 2014; Karabulut, 2015; Özmen, 2006) görülmektedir. Bu sinılllık, ülkemizde özel gereksinimli öğrencilerde kullanılan stratejilerin özellikleri ile ilgili profil oluşturmasını, ne tür strateji sınırlılıkları gözlendiği bulgularının ortaya çıkarılmasını güçleştirmektedir. Bu bağlamda özellikle, ÖG olan öğrencilerin kullandıkları bilişsel ve üstbilişsel stratejilerin sesli düşünme protokolü ile incelenmesi gerekmektedir. Bu araştırmaların özellikle ÖG olan öğrencilere matematik problemi çözme öğretiminde hazırlanacak müdahale programlarına 1şık tutması beklenebilir. Diğer yandan, son yillarda üstbilişin değerlendirilmesine yönelik, eş zamanlı olan ve olmayan yöntemlerin bir arada ya da belirtilen yöntemlerin birden fazla sayıda aynı araştırmada kullanılmasının gerekliliğinden söz edilmektedir (Desoete ve diğ., 2001; Veenman ve Spaans 2005). Ülkemizde değerlendirme yöntemi olarak öğrencilerin kullandığı üstbilişsel ve bilişsel stratejileri hem eş zamanlı hem de eş zamanlı olmayan değerlendirme yöntemleri ile betimsel olarak inceleyen araştırmalar bulunmamaktadır. $\mathrm{Bu}$ bağlamda, araştırmaların planlanmasının matematik problemi çözmede kullanılan bilişsel ve üstbilişsel stratejilerin değerlendirilmesi açısından önem taşıdığı düşünülmektedir. Son olarak üstbilişin, üstbilişsel strateji, bilgi ve deneyim gibi farklı bileşenlerden oluştuğu göz önüne alınarak, ÖG olan öğrencilerin matematik problemi çözmede bu bileşenler arasındaki ilişkiyi inceleyen veya üstbilişsel işlevlerin tüm boyutları ile ele alındığı araştırmalar planlanabilir. 


\section{Kaynaklar}

Akdur, T. E. (1996). Yardımlaşarak bilgisayar ortamında kavram haritalarının hazırlanmasının, lise seviyesindeki ögrencilerin fizik başarısı, fizik dersine ve kavram haritalamaya yönelik tutumları ve biliş bilgisi becerileri üzerindeki etkisi [Effect of collaborative computer based concepy mapping on students physics achievement, attitude toward physics, attitude toward concept mapping and metacognitive skills at high school level] (Unpublished master's thesis, Middle East Technical University, Institute of Science, Ankara, Turkey). Retrieved from http://tez.yok.gov.tr/UlusalTezMerkezi. (Thesis Number 56781)

Baker, L., \& Cerro, L. C. (2002). Assessing metacognition in children and adults. In G. Schraw \& J. C. Impara (Eds.), Issues in the measurement of metacognition (pp. 99-145). Lincoln, Nebraska: Buros Institute of Mental Measurements.

Billingsley, F., White, O. R., \& Munson, R. (1980). Procedural reliability: A rationale and example. Behavioral Assessment, 2(3), 229-241.

Brown, A. L., Campione, J. C., \& Barclay, C. R. (1979). Training and self-checking routines for estimating test readiness: Generalization from list learning to prose recall. Child Development, 50(2), 501-512.

Bryant, D. P., Bryant, B. R., \& Hammill, D. D. (2000). Characteristic behaviors of students with LD who have teacher-identified math weaknesses. Journal of Learning Disabilities, 33(2), 168-177.

Bryant, D. P., Smith, D. D., \& Bryant, B. R. (2008). Teaching students with special needs in inclusive classrooms. Boston, MA: Allyn \& Bacon.

Chan, L. K. S. (1996). Motivational orientations and metacognitive abilities of intellectually gifted students. Gifted Child Quarterly, 40(4), 184-193.

Çakıroğlu, A. (2007). Üstbiliş [Metacognition]. Türkiye Sosyal Araştırmalar Dergisi, 11(2), 6-21.

Çiçekçioğlu, D. (2003). Bilişsel ve biliş ötesi okuma stratejilerinin direk ve tümleşik olarak bilinçlendirme seviyesinde ögretiminin okuma yeterliliğine ve strateji kullanımına etkileri [The effects of direct and integrated instruction of cognitive and metacognitive reading strategies at awareness-raising level on reading proficiency and strategy use] (Unpublished master's thesis, Middle East Technical University, Institute of Social Sciences, Ankara, Turkey). Retrieved from http://tez.yok.gov.tr/UlusalTezMerkezi. (Thesis Number 140299)

Demir-Gülşen, M. (2000). Olasılık ve matematik başarısını bilişsel, bilişüstü ve duyuşsal değişkenlerle açıklayıcı bir model çalışması [A model to investigate probability and mathematics achievement in terms of cognitive, metacognitive and affective variables] (Unpublished master's thesis, Bogazici University, Institute of Science, Istanbul, Turkey). Retrieved from http://tez.yok.gov.tr/UlusalTezMerkezi. (Thesis Number 95378)

Desoete, A., \& Roeyers, H. (2002). Off-line metacognition: A domain-specific retardation in young children with learning disabilities? Learning Disability Quarterly, 25(2), 123-139.

Desoete, A., Roeyers, H., \& Buysse, A. (2001). Metacognition and mathematical problem solving in grade 3. Journal of LearningDisabilities, 34(5), 435-449.

Doğan, A. (2013). Üstbiliş ve üstbilişe dayalı öğretim [Metacognition and metacognition based teaching]. Middle Eastern \& African Journal of Educational Research, 3(2), 6-20.

Doğanay-Bilgi, A., \& Özmen, E. R. (2014). Uyarlanmış çok ögeli bilişsel strateji öğretiminin zihinsel engelli öğrencilerin metin anlama sürecinde kullanılan ÜBS bilgisini kazanmalarında etkisi [The impact of modified multi-component cognitive strategy instruction in the acquisition of metacognitive strategy 
knowledge in the text comprehension process of students with mental retardation]. Kuram ve Uygulamada Eğitim Bilimleri, 14(2), 7-14.

Ekenel, E. (2005). Matematik dersi başarısı ile bilişötesi öğrenme stratejileri ve sınav kaygısının ilişkisi [The relation between metacognitive learning strategies and examination anxiety and success in mathematic lessons] (Unpublished master's thesis, Anadolu University, Institute of Educational Sciences, Eskisehir, Turkey). Retrieved from http://tez.yok.gov.tr/UlusalTezMerkezi. (Thesis Number 187959)

Ericsson, K. A., \& Simon, H. A. (1980). Verbal reports as data. Psychological Review, 87(3), 215-251.

Ericsson, K. A., \& Simon, H. A. (1993). Protocol analysis: Verbal reports as data (revised edition). Cambridge, MA: The MIT Press

Flavell, J. H. (1979). Metacognition and cognitive monitoring. A new area of cognitive developmental inquiry. American Psychologist, 34(10), 906-911.

Geary, D. C. (2004). Mathematics and learning disabilities. Journal of Learning Disabilities, 37(1), 4-15.

Gelen, İ. (2003). Bilişsel farkındalık stratejilerinin Türkçe dersine ilişkin tutum, okuduğunu anlama ve kalıcılı̆ga etkisi [The effects of metacognitive strategies on attitudes toward Turkish course, reading comprehension achievement and retention] (Unpublished doktorate thesis, Cukurova University, Institute of Social Sciences, Adana, Turkey). Retrieved from http://tez.yok.gov.tr/UlusalTezMerkezi. (Thesis Number 125716)

House, A. E., House, B. J., \& Campbell, M. B. (1981). Measures of interobserver agreement: Calculation formulas and distribution effects. Journal of Behavioral Assessment, 3(1), 37-57.

Jacobs, J. E., \& Paris, S. G. (1987). Children's metacognition about reading: Issues in definition, measurement, and instruction. Educational Psychologist, 22(3), 255-278.

Johnstone, C. J., Bottsford-Miller, N. A., \& Thompson, S. J. (2006). Using the think aloud method (cognitive labs) to evaulate test design for students with disabilities and English language learners (Technical Report 44). Minneapolis, MN: University of Minnesota, National Center on Educational Outcomes.

Karabulut, A. (2015). Anla ve çöz stratejisinin hafif düzeyde zihinsel yetersizliği olan ögrencilerin matematik problemi çözme becerisindeki etkisinin belirlenmesi [Effectiveness of anla ve çöz! strategy instruction on math problem solving of students with mild intellectual disabilities] (Unpublished doktorate thesis, Gazi University, Institute of Educational Sciences, Ankara, Turkey). Retrieved from http://tez.yok.gov.tr/UlusalTezMerkezi. (Thesis Number 388208)

Karakelle, S., \& Saraç, S. (2010). Üst biliş hakkında bir gözden geçirme: Üst biliş çalışmaları mı yoksa üst bilişsel yaklaşım mı? [A review on metacognition: metacognitive research or metacognitive approach?]. Türk Psikoloji Yazılarl, 13(26), 45-60.

Karakelle, S., \& Saraç, S. (2007). Çocuklar için üst bilişsel farkındalık ölçeği (ÜBFÖ-Ç) A ve B formları: Geçerlik ve güvenirlik çalışması [Validity and factor structure of Turkish versions of the metacognitive awareness inventory for children (Jr. MAI) - a and b forms]. Türk Psikoloji Yazllarl, 10(20), 87-103.

Kingsdorf, S., \& Krawec, J. (2014). Error analysis of mathematical word problem solving across students with and without learning disabilities. Learning Disabilities Research \& Practice, 29(2), 66-74.

Kluwe, R. H. (1982). Cognitive knowledge and executive control: Metacognition. In D. R. Griffin (Ed.), Animal mind-human mind (pp. 201-224). New York: Springer-Verlag.

Küçük-Özcan, Z. Ç. (2000). Bilişüstü becerilerinin 6. sınıf öğrencilerine ögrretilmesi [Teaching metacognitive strategies to 6th grade students] (Unpublished master's thesis, Bogazici University, Institute of Science, 
Istanbul, Turkey). Retrieved from http://tez.yok.gov.tr/UlusalTezMerkezi. (Thesis Number 95435)

Malpass, J. R., O’Neil, J. H. F., \& Hocevar, D. (1999). Self-regulation, goal orientation, selfefficacy, worry, and high-stakes math achievement for mathematically gifted high school students. Roeper Review, 21(4), 281289.

Miller, S., \& Mercer, C. (1997). Education aspects of mathematics disabilities. Journal of Learning Disabilities, $30(1), 47-56$

Minnaert, A., \& Janssen, P. J. (1999). The additive effect of regulatory activities on top of intelligence in relation to academic performance in higher education. Learning and Instruction, 9(1), 77-91.

Montague, M. (1992). The effects of cognitive and metacognitive strategy instruction on the mathematical problem solving of middle school students with learning disabilities. Journal of Learning Disabilities, 25(4), 230248.

Montague, M., \& Applegate, B. (1993a). Mathematical problem solving characteristics of middle school students with learning disabilities. Journal of Special Education, 27(2), 175-201.

Montague, M., \& Applegate, B. (1993b). Middle school students mathematical problem solving: An analysis of think-aloud protocols. Learning Disabilities Quarterly, 16(1), 19-32.

Montague, M., \& Bos, C. (1990). Cognitive and metacognitive characteristics of eighth-grade students' mathematical problem solving. Learning and Individual Differences, 2(3), 109-127.

Montague, M., Applegate, B., \& Marquard, K. (1993). Cognitive strategy instruction and mathematical problemsolving performance of students with learning disabilities. Learning Disabilities Research and Practice, $8(4), 223-232$.

Muhtar, S. (2006). Üstbilişsel strateji eğitiminin okuma becerisinde öğrenci başarısına olan etkisi [Effects of training university EFL students in metacognitive strategies for reading] (Unpublished master's thesis, Ankara University, Institute of Social Sciences, Ankara, Turkey). Retrieved from http://tez.yok.gov.tr/UlusalTezMerkezi. (Thesis Number 191440)

Namlu, A. G. (2004). Bilişötesi öğrenme stratejileri ölçme aracının geliştirilmesi: Geçerlilik ve güvenirlik çalışması [Metacognitive learning strategies scale: A study of reliability and validity]. Anadolu Üniversitesi Sosyal Bilimler Dergisi, 4(2), 123-141.

National Council of Teachers of Mathematics (2000). Curriculum and evaluation standards for school mathematics (Commission on Standards for School Mathematics, working draft). Reston, VA: NCTM.

Ostad, A., \& Sorensen, P.M. (2007). Private speech and strategy-use patterns: Bidirectional comparisons of children with and without mathematical difficulties in a developmental perspective. Journal of Learning Disabilities, 40(1), 2-14.

Özcan, Z, Ç. (2007). Sınıf öğretmenlerinin derslerinde bilişüstü beceri geliştiren stratejileri kullanma özelliklerinin incelenmesi [Investigation of primary school teachers use of metacognitive strategies in their lessons] (Unpublished doktorate thesis, Marmara University, Institute of Educational Sciences, Istanbul, Turkey). Retrieved from http://tez.yok.gov.tr/UlusalTezMerkezi. (Thesis Number 206211)

Özmen, R. (2006). The effectiveness of modified cognitive strategy instruction in writing on mildly mentally retarded Turkish students. Exceptional Children, 72(3), 281-294.

Özmen, R. (Ed.). (2017). Öğrenme güçlüğü sınıf içi destek seti, öğrenme güçlüğü hakkında temel bilgiler ve uygulamalar [Inner classroom learning disability instruction package, theorical information and application about learning disabilities]. Ankara: Eğiten Kitap. 
Özsoy, G. (2007). Illköğretim beşinci sınıf düzeyinde üstbiliş stratejileri ögrretiminin, problem çözme başarısına etkisi [The effect of metacognitive instruction on problem solving achievement of fifth grade primary school students] (Unpublished doktorate thesis, Gazi University, Institute of Educational Sciences, Ankara, Turkey). Retrieved from http://tez.yok.gov.tr/UlusalTezMerkezi. (Thesis Number 207154)

Paris, S. G., \& Flukes, J. (2005). Assessing children's metacognition about strategic reading. In S. Israel, C. C. Block, K. Bauserman ve K. Kinnucan-Welsch (Eds.), Metacognitionin literacy learning: Theory, assessment, instruction, andprofessional development, (pp. 121-139). Mahwah, NJ: Lawrence Erlbaum Associates.

Perleth, C. (1992). Strategy use and metamemory in gifted and average primary school children. In K. A. Heller, \& E. A. Hany (Eds), Competence and responsibility, the third European conference of the European council for high ability (pp. 46-52). Seattle, WA: Hogrefe \& Huber.

Pilten, P. (2008). Üstbiliş stratejileri öğretiminin ilköğretim beşinci sınıf öğrencilerinin matematiksel muhakeme becerilerine etkisi. [The effect of metacognitive instruction on problem solving achievement of fifth grade primary school students] (Unpublished doktorate thesis, Gazi University, Institute of Educational Sciences, Ankara, Turkey). Retrieved from http://tez.yok.gov.tr/UlusalTezMerkezi. (Thesis Number 214521)

Pressley, M., \& Afflerbach, P. (1995). Verbal protocols of reading: The nature of constructively responsive reading. Hillsdale, NJ: Erlbaum.

Prins, F. J., Veenman, M. V. J., \& Elshout, J. J. (2006). The impact of intellectual ability and metacognition on learning: New support for the threshold of the problematicity theory. Learning and Instruction, 16(4), 374-387.

Rosenzweig, C., Krawec, J., \& Montague, M. (2011). Metacognitive strategy use of eighth-grade students with and without learning disabilities during mathematical problem solving: a think-aloud analysis. Journal of Learning Disabilities, 44(6) 508-520.

Schraw, G., \& Dennison, R. (1994). Assessing metacognitive awareness. Contemporary Educational Psychology, 19(4), 460-475.

Schraw, G., \& Moshman, D. (1995). Metacognitive Theories. Educational Psychology Review, 7(4), $351-371$.

Schudmak, W. (2014). Metacognitive strategies employed during mathematical problem solving: a comparative case study of fifth graders who are gifted and have ADHD (Doctoral dissertation, George Mason University). Retrieved from http://digilib.gmu.edu/jspui/bitstream/handle/1920/8867/Schudmak_gmu_0883E_10569.pdf?sequence= 1

Shaughnessy, M. F., Veenman, M. V. J., \& Kleyn-Kennedy, C. (2008). Metacognition: A recent review of research, theory and perspectives. NY: Nova Science Publishers, Inc.

Shin, M., \& Bryant, D. P. (2015). A synthesis of mathematical and cognitive performances of students with mathematics learning disabilities. Journal of Learning Disabilities, 48(1), 96-112.

Shraw, G., \& Graham, T. (1997). Helping Gifted students Develop Metacognitive Awareness. Roeper Review, 20(1), 4-8.

Sperling, R. A., Howard, B. C, Staley, R., \& DuBois, N. (2004). Metacognition and self-regulated learning constructs. Educational Research and Evaluation, 10(2), 117-139. 
Swanson, H. L. (1990). Influence of metacognitive knowledge and aptitude on problem solving. Journal of Educational Psychology, 82(2), 306-314.

Swanson, H. L. (1992). The relationship between metacognition and problem solving in gifted children. Roeper Review, 15(1), 43-49.

Swanson, H. L., \& Jerman, O. (2006). Math Disabilities: A Selective Meta-Analysis of the Literature. Review of Educational Research, 76(2), 249-274.

Sweeney, C. M. (2010). The metacognitive functioning of middle school students with and without learning disabilities during mathematical problem solving (Doctoral dissertation, Miami University). Retrieved from http://scholarlyrepository.miami.edu/cgi/viewcontent.cgi?article=1432\&context=oa_dissertations

Tunçman, N. (1994). Üniversite öğrencilerinin üst biliş düzeylerinin çeşitli değişkenler açısından incelenmesi [Effects of training preparatory school EFL students at Middle East Technical University in a metacognitive strategy for reading academic texts] (Unpublished master's thesis, Bilkent University, Institute of Social Sciences, Ankara, Turkey). Retrieved from http://tez.yok.gov.tr/UlusalTezMerkezi. (Thesis Number 36176)

Van Hout-Wolters, B. (2000). Assessing active self-directed learning. In R. Simons, J. van der Linden, \& T. Van Hout-Wolters, B. (2000). Assessing active self-directed learning. In R. Simons, J. van der Linden, \& T. Duffy (Eds.), New learning (pp. 83-101). Dordrecht: Kluwer.

Veenman, M. V. J., \& Spaans, M. A. (2005. Relation between intellectual and metacognitive skills: Age and task differences. Learning and Individual Differences, 15(2), 159-176.

Veenman, M. V. J., Kok, R., \& Blöte, A. W. (2005). The relation between intellectual and metacognitive skills in early adolescence. Instructional Science, 33(3), 193-211.

Yavuz, D. (2009). Öğretmen adaylarının özyeterlik algıları ve üstbilişssel farkındalıklarının çeşitli değişsenler açısından incelenmesi [Study on preservice teachers? Self-efficacy perceptions and metacognitive awareness in terms of different variables] (Unpublished master's thesis, Zonguldak Karaelmas University, Institute of Social Sciences, Zonguldak, Turkey). Retrieved from http://tez.yok.gov.tr/UlusalTezMerkezi. (Thesis Number 239298)

Yore, L. D., \& Craig, M. T. (1992). Middle school students' metacognitive knowledge about science reading and science text: Objective assessment, validation and results (Reports Research/Technical (143). East Lansing, MI: National Center for Research on Teacher Learning.

Yüzbaşığlu, Z. T. (1991). Üniversite öğrencilerinin üst biliş düzeylerinin çeşitli değiş̧kenler açısından incelenmesi [Turkish university EFL students metacognitive strategies and beliefs about language learning] (Unpublished master's thesis, Bilkent University, Institute of Social Sciences, Ankara, Turkey). Retrieved from http://tez.yok.gov.tr/UlusalTezMerkezi. (Thesis Number 15342). 


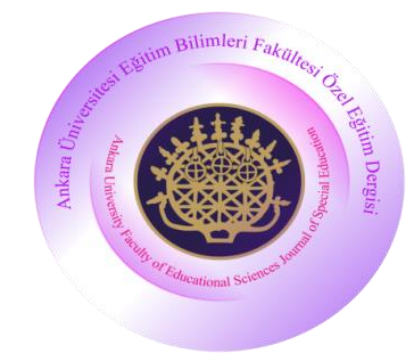

REVIEW

\section{Ankara University Faculty of Educational Sciences Journal of Special Education}

Year: 2018, Volume: 19, No:1, Page No: 155-180

DOI: 10.21565/ozelegitimdergisi.299494

\title{
Analysis of Mathematical Problem Solving Process of Students with Learning Disability: Implementation of Think Aloud Protocol
}

\author{
Ufuk Özkubat* \\ Gazi University
}

\author{
E. Rüya Özmen** \\ Gazi University
}

\begin{abstract}
The purpose of this study is to identify the think aloud protocols utilized in the assessment of cognitive and metacognitive strategies that are used in the process of mathematical problem solving by the students with learning disabilities (LD). Regarding the purpose of the study, the strategies required in mathematical problem solving are firstly clarified, and students' mathematical problem solving difficulties are stated. Secondly, the use of think aloud protocols for the assessment ofcognitive and metacognitive strategies in mathematical problem solving are identified, and the related research findings are discussed. Thirdly, the information about the educational implications of assessment results concerning the application of think aloud protocol is provided. In conclusion section, suggestions are made for addressing the needs of research focused on cognitive and metacognitive strategies used by students with learning disabilities and their peers.

Keywords: Learning disability, mathematical problem solving, cognitive and metacognitive strategies, think aloud protocols.
\end{abstract}

\section{Recommended Citation}

Özkubat, U., \& Özmen, E. R. (2018). Analysis of mathematical problem solving process of students with learning disability: Implementation of think aloud protocol. Ankara University Faculty of Educational Sciences Journal of Special Education, 19(1), 155-180. doi: 10.21565/ozelegitimdergisi.299494

*Corresponding Author: Ress. Asst., Ankara, E-mail: ufukozkubat@ gazi.edu.tr, https://orcid.org/0000-0002-9626-5112

**Prof. Dr., E-mail: ruyaozmen@ @otmail.com, https://orcid.org/0000-0002-0226-1672 
It is important for students to gain fundamental academic skills for achieving success in their school lives and living independently in the society. The fundamental academic skills intended to be gainedare as follows: reading, writing, basic operations, and problem solving. In 2000 the National Council of Teacher of Mathematics (NCTM) released their Principles and Standards for School Mathematics. This document emphasized conceptual understanding and a problem solving approach to mathematics. NCTM advocated abandoning instruction that focused on having students passively recite learned knowledge and encouraged teachers to actively engage students in meaningful communication about math and develop their ability to understand and make connections across math concepts (NCTM, 2000). In the area of mathematics, it is stated that the students with learning disabilities have difficulties regarding writing numbers, performing mathematical operations, remembering operational processes and details, performing the operations with appropriate steps and the language or terminology of mathematics (Bryant, Smith and Bryant, 2008; Bryant, Bryant and Hammill, 2000; Geary, 2004; Kingsdorf and Krawec, 2014). Furthermore, their limitation in the area of language and reading skills cause the students with learning disabilities to mix up the mathematical terminology such as addition, subtraction, and borrowing.

Mathematical problem solving which is one of the skills which the students with learning disabilities have a difficulty (Montague, Applegate and Marquard, 1993). Mathematical problem solving requires the students to analyze and interpret the information in the problem and make decisions regarding which operations to use and regarding the operation steps. Problem solving also requires the students to know how to apply the mathematical concepts and use their calculation skills in new or different environments (Montague et al., 1993). Students with learning disabilities are less likely to effectively use strategies and experience difficulty developing their own strategies when compared with students without learning disabilities (Montague and Applegate, 1993b; Ostad and Sorenson, 2007; Rosenzweig, Krawec and Montague, 2011; Sweeney, 2010).

Mathematical problem solving involves the integration of several cognitive and metacognitive strategies. The cognitive strategies defined as all strategies developed and used from starting with reading the problem to checking the solution and process; and metacognitive strategies defined as a structure composing of a certain number of operations and strategies included self-monitoring in performing the mathematical operation solving and controlling the cognitive operations. Montague's model originated from research in general problem solving, mathematical problem solving, self-regulation, and affective variables related to successful problem solving (Montague, 1992). Self-regulation refers to a process in which students actively monitor their performance (metacognitive) while selecting from among strategies (cognitive) in order to attain a goal. This process is cyclical and encompasses various cognitive and metacognitive activities, which undergo a series of interactions in order to achieve a predetermined end. The cognitive processes and metacognitive strategies presented in Montague's model reflect the strategies that expert problem solvers know and use effectively (Montague et al., 1993b). Montague identified seven cognitive processes necessary for successful problem solving and developed a metacognitive routine to facilitate their use. With the help of a mnemonic, RPV-HEGC, students learn the seven cognitive processes to effectively solve math problems and the metacognitive strategies to monitor their application. The seven cognitive processes are: read (for understanding), paraphrase (your own words), visualize (a picture or diagram), hypothesize (a plan to solve the problem), estimate (make a prediction), compute (do the arithmetic), and check (make sure everything is right). The metacognitive strategies include self-instruction, self-questioning, and self-checking in the form of a routine that helps students gain access to processes and monitor their application as they solve math problems (Montague, 1992).

Several studies were located that examined the mathematical and/or cognitive variables conceivably associated with learning disabilities. In a review, Swanson and Jerman (2006) quantitatively analyzed findings from studies published between 1983 and 2002 on the cognitive performance of kindergarten through adolescent students with learning disabilities compared to typically achieving students, students with learning disabilities, and students with comorbid disorders in ten areas including literacy-reading, problem solving-verbal, naming speed, problem solving-visual-spatial, long-term memory, short-term memory-words, short-term memory-numbers, 
working memory-verbal, working memory-visual-spatial, and attention. Students with learning disabilities demonstrated higher cognitive deficits on measures of verbal problem solving, naming speed, verbal working memory, visual-spatial working memory, and long-term memory compared with age-matched typically achieving peers. Students with learning disabilities had less cognitive deficits than students with comorbid disorders on measures of literacy, visual-spatial problem solving, long-term memory, short-term memory, and verbal working memory. Likewise, Shin and Bryant (2015), synthesize the findings from 23 articles that compared the mathematical and cognitive performances of students with learning disabilities to students with learning disabilities in mathematics and reading, age- or grade-matched students without learning disabilities, and mathematical-ability-matched younger students without learning disabilities. Overall results revealed that students with learning disabilities exhibited higher word problem solving abilities and no significant group differences on working memory, long-term memory, and metacognition measures compared to students with learning disabilities in mathematics and reading. Findings also revealed students with learning disabilities demonstrated significantly lower performance compared to age- or grade-matched students without learning disabilities on both mathematical and cognitive measures. Comparison between students with learning disabilities and younger students without learning disabilities revealed mixed outcomes on mathematical measures and generally no significant group differences on cognitive measures.

The cognitive strategies defined as all strategies developed and used (from starting without reading the problem to checking the solution and process); and metacognitive strategies among the metacognitive components defined as a structure composed of a certain number of operations and strategies defined as self monitoring in performing the mathematical operation solving and controlling the cognitive operations play a significant role in order to be successful in this part. As is seen, it is stated that the interrelated cognitive and metacognitive strategies should be inseparablydiscussedwhen analyzing since the limitedness seen in either of the cognitive and metacognitive strategy usages affect one another component.

\section{Think Aloud Protocols}

Generally, the verbal reporting techniques are used in the assessment of cognitive and metacognitive strategies (Desoete and Roeyers 2002; Ericson and Simon, 1993; Van Hout-Wolters, 2000; Veenman, Kok and Blöte, 2005). These techniques are divided into three groups as simultaneous, non-simultaneous, and the one in which the both are used together (multi-method arrangements) by categorizing according to the time in which the performance regarding the cognitive and metacognitive dimension analyzed with the assessment is delivered (Karakelle and Saraç, 2010). Non-simultaneous techniques are usually the interviewing and question list technique (Chan, 1996; Jacobs and Paris, 1987; Malpass, O’Neil and Hocevar, 1999; Minnaert and Janssen, 1999; Perleth, 1992; Swanson, 1992; Yore and Craig, 1992). Non-simultaneous techniques are research methods that aim at measuring individual's attitudes, behaviors, feelings or thoughts. In questionnaires, students record their thinking in response to standardized questions. In interviews, student responses to fixed or open-ended questions regarding thinking are recorded. Non-simultaneous techniques remain among the most popular choice for measuring cognitive phenomena due in part to its practical and information-rich nature (Van Hout-Wolters, 2000). All of these methods, however, are dependent upon the individual's ability to recall information and are thus subject to memory failure. Additionally, they offer "after-the-fact" descriptions or projections of thinking that can be incomplete and biased. Since students may adjust their responses to fit what they expect the researcher wants to hear, these methods may be inaccurate or altogether false reports (Karakelle and Saraç, 2010).

One of the simultaneous techniques used in the assessments of cognitive and metacognitive strategies is the think aloud protocols. Think aloud protocols are defined as an assessment technique based on the verbal performance of the participants in which the participants state aloud every thing which they think of and do during the tasks such as reading a text or mathematical problem solving (Montague and Applegate, 1993b; Ostad and Sorenson, 2007; Rosenzweig et al., 2011; Swanson, 1990; Sweeney, 2010; Veenman and Spaans, 2005). Analyzing students' actual strategy use is best achieved through concurrent verbal reports, such as think aloud protocols since researchers have direct access to the ongoing mental processing occurring during task completion. 
The data obtained from the think aloud protocols are generally recorded with devices such as a voice recorder and camera, and a transcription of the recorded data is prepared (Van Hout-Wolters, 2000). Then the articulations in the transcriptions are evaluated by analyzing them in accordance with the cognitive and metacognitive strategies (Rosenzweiget al., 2011; Sweeney, 2010).

Think-aloud protocols are a method of collecting metacognitive data that provide rich verbal data regarding a student's reasoning abilities during problem solving activities (Van Hout-Wolters, 2000). Think-aloud protocols are primarily used to obtain information regarding information on cognitive processing (Ericsson and Simon, 1993). This can be done concurrently, while the participant is engaged in problem solving. Thinking out loud does not affect cognitive processes or performance speed (Ericsson and Simon, 1993) and may provide a more accurate account of applied metacognitive skills since they do not require the students to remember what they have been thinking. Students are simply asked to verbalize what they are thinking as they are thinking it. This method may be less subject to the students' interpretation. The difficulty with think-aloud protocols is that not all students are capable of consciously expressing routines and strategies that may have already been internalized to the point of being automated and therefore might provide an incomplete account of metacognitive functioning (Veenman et al., 2005).

\section{Implementing Think Aloud Protocols}

Prior to the think aloud procedure, the practitioner trains the student by the following manner. First, the practitioner explains the purpose of the study and the reason why a think aloud is a good way to understand how people solve math problems (Montague and Applegate, 1993b; Ostad and Sorenson, 2007; Rosenzweig et al., 2011; Sweeney, 2010). The practitioner reads the following script; "I am interested in how students solve problems, so I want to ask you to solve three problems for me and let me listen to how you solve them. I am not interested in how you are thinking about the problem to solve. What you say is really important, so I am going to use a tape recorder to make sure I don't forget anything." (Johnstone, Bottsford-Miller, and Thompson, 2006). Second, the practitioner models thinking out loud using metacognitive strategies like self-questioning, and selfmonitoring. Then the student is given an opportunity to practice thinking out loud while solving two different problems. The practitioner encourages the student to speak with appropriate volume and clarity. In the implementation stage, the practitioner asks the student to solve the three math word problems while thinking out loud. The session is recorded and transcribed to produce verbal protocols (Sweeney, 2010).

Verbalizations are coded as cognitive verbalizations (i.e., verbalizations related to specific cognitive processes), productive metacognitive verbalizations (i.e., verbalizations related to finding a solution), or nonproductive metacognitive verbalizations (i.e., verbalizations that have no bearing on progress toward problem solution). The cognitive, productive metacognitive, and nonproductive metacognitive verbalizations are scored to provide for each problem type. These frequency counts are transformed into percentages. To illustrate, the percentage of productive metacognitive verbalizations and cognitive verbalizations in the problem was calculated by dividing the frequency count of productive metacognitive verbalizations and cognitive verbalizations by the total number of verbalizations across categories. The quotient was multiplied by 100 to produce the percentage of productive metacognitive verbalizations for the problem (Rosenzweig et al., 2011). Montague's model of mathematical problem solving, which includes seven cognitive processes (i.e., reading, paraphrasing, visualizing, hypothesizing, estimating, computing, and checking) and three metacognitive strategies (i.e., self-instruction, selfquestioning, and self-monitoring) served as a base for the coding system.

To determine inter rater agreement, two researchers coded and then compared think-aloud protocols to establish an initial agreement. Aniterative process of discussing and resolving disagreements is used until an agreementis reached regarding the coding. All protocols are returned to the pool and then rated by both researchers. Inter-rater agreement is calculated by dividing the number of agreements by the number of agreements plus disagreements and multiplying by 100 (House, House and Campbell, 1981). 


\section{The Results of the Assessment Carried Out with the Think Aloud Protocol}

Researchers have confirmed that metacognition is vital to academic success and is particularly important to successful problem solving. Swanson (1990) analyzed the think aloud protocols of 56 students in grades four and five. The study provided interesting information regarding the functional role of metacognition and its relationship to cognitive ability. Students were grouped based on performance on a 17-item questionnaire that assessed metacognition in the general domain of problem solving to form high and low metacognitive groups. Four groups were formed: high aptitude-high metacognition, high aptitude-low metacognition, low aptitude-high metacognition, and low aptitude-low metacognition. Students were then audio-recorded solving two tasks. Their think-aloud protocols were transcribed and coded. Results showed that the high metacognitive students outperformed low metacognitive students regardless of aptitude. These findings suggest that metacognition may be independent of general aptitude and have more predictive power for future success than general intelligence. Montague and Applegate (1993b) used think-aloud protocols to examine the self-regulation and strategy use of 81 students. The students were provided with 10 minutes of think-aloud instruction using two verbal reasoning problems. They were then asked to solve a one-step, a two-step, and a three-step math word problem while thinking aloud. It was concluded that there were no differences in cognitive or metacognitive verbalizations for problem one step. Gifted students made significantly more cognitive but not metacognitive verbalizations than students with learning disability for problem two step and also significantly made more cognitive and metacognitive verbalizations than students with learning disability and average achievers for problem three step. These findings support the metacognition is activated when individuals are faced with challenging problems. However, a student's perception of the difficulty of the problem may have an effect on their persistence in solving the problem and decision to activate their self-guiding metacognitive strategies. Ostad and Sorenson (2007) investigated patterns of private speech and strategy use and their interaction in 134 children with and without mathematical difficulties while solving mathematical problems. In this study, students were each assigned to one of three grade groups (23/4-5/6-7). Using a cross-sectional design, the researchers observed the participants individually during two laboratory sessions. Their results showed that task-relevant speech is positively correlated with self-control and successful task completion during problem solving. Children with mathematical difficulties consistently used more counting on one's fingers strategies than students without mathematical difficulties whereas students without mathematical difficulties used more accessing information from one's memory strategies. These findings support the developmental lag hypothesis in that the poor metacognitive skills of children with learning disability are the result of immature, rather than absent, metacognitive skills. Sweeney (2010), investigated the metacognitive skills of students with learning disabilities, low-achieving students, and average-achieving students within the context of math problem solving. Students solved three math word problems while thinking aloud. Results indicated that students with learning disabilities demonstrated a different pattern of metacognitive function than averageachieving students and low-achieving students. Students across ability groups look relatively equivalent in the quantity of metacognitive skills. However, when discriminating between the type and quality of the metacognitive skills employed, ability group differences were evident. All students increased their non productive metacognitive verbalizations from the 2 -step to the 3-step problem, which suggests that they all perceived the 3-step problem to be more difficult than the other two problems. Only students with learning disabilities, however had a significant difference between their productive metacognitive verbalizations and non productive metacognitive verbalization for the 3-step problem, indicating that these students either lacked the necessary strategies to solve the problem or were unable to apply the strategies they did possess since they may have perceived this problem to be beyond their problem solving abilities and gave up. Rosenzweig et al. (2011), investigated the metacognitive abilities of students with learning disability as they engaged in math problem solving and to determine processing differences between these students and their low- and average-achieving peers. Students thought out loud as they solved three math problems of increasing difficulty. Protocols were coded and analyzed to determine the frequency of cognitive verbalizations and productive and nonproductive metacognitive verbalizations. Results indicated different patterns of metacognitive activity for ability groups when the type of metacognitive verbalization and problem difficulty were considered. The interaction between ability and problem difficulty was significant. Low-achieving students 
produced fewer metacognitive verbalizations for the two-step problem compared with the one-step problem, significant increase in metacognitive verbalizations from the two-step to the three-step problem was found for all three ability groups. The interaction between metacognitive verbalization type and problem difficulty was also significant. As problems became more difficult, significant differences in nonproductive verbalizations were found. The interaction of ability, problem difficulty, and metacognitive verbalization type was significant, as problems became more difficult, the type of metacognitive verbalizations varied across ability groups. Students with learning disability significantly increased their non productive metacognitive verbalizations from the onestep problem to the three-step and from the two-step to the three-step problem.

\section{The Reflections of the Think Aloud Protocols}

Think aloud procedure may be useful for teachers interested in determining specific areas of weakness in students' processing skills, different types of errors, and strategy use during problem solving. Think aloud data can provide information in accessible through paper and pencil performance measures. The information can then be used to create processing profiles of students, and instruction based on specific deficits can be differentiated to accommodate an individual student's needs.

\section{Conclusion}

The research studies carried out on metacognition area have increased rapidly since Flavell (1979) came up with the term of metacognition. It is seen that while in the international literature investigations related to metacognition have been carried out since 1978 (Brown, Campione and Day, 1981; Kluwe, 1982) in Turkey investigations in this area have begun since the 1990s (Doğan, 2013). In Turkey metacognitive literature was generally carried out with normal achieving students were related to language teaching (Muhtar, 2006; Tunçman, 1994; Yüzbaş1oğlu,1991), mathematics education (Demir-Gülşen, 2000; Ekenel, 2005; Küçük-Özcan, 2000; Pilten, 2008), teacher education (Özcan, 2007; Yavuz, 2009), computer teaching (Akdur, 1996), reading and listening comprehension (Aral, 1999; Çakıroğlu,2007; Çiçekçioğlu, 2003; Gelen, 2003), scale development (Karakelle and Saraç, 2007; Namlu, 2004) and problem solving (Özsoy, 2007). Regarding the area of special education, it is seen that metacognitive or cognitive strategy studies are limited to the students with intellectual disability (Doğanay-Bilgi and Özmen, 2014; Karabulut, 2015; Özmen, 2006). This limited research makes it difficult to produce strategy profile about the students with learning disabilities. Within this context, further research studies are needed to determine the cognitive and metacognitive strategies for problem solving used by students with learning disabilities. These research studies will provide a basis for preparing intervention programs. 
ÖĞRENME GÜÇLÜĞÜ OLAN ÖĞRENCILERIN MATEMATIK PROBLEMİ ÇÖZME SÜREÇLERINININ İNCELENMESI: SESLİ DÜŞÜNME PROTOKOLÜ UYGULAMASI

\section{Ekler}

Ek A1. Sesli Düşünme Protokolü Uygulaması Örneği

\begin{tabular}{cccc}
\hline Katılımcı Numarası & Yetenek Grubu & Problem Çözüm Süresi & $\begin{array}{c}\text { Problem Çözüm } \\
\text { Doğruluğu } \\
\text { Yanllş }\end{array}$ \\
\hline 1 & Öğrenme Güçlüğü & $37 \mathrm{sn}$ & \\
\hline \multicolumn{3}{c}{ Problem } \\
\hline
\end{tabular}

Bir akvaryumda 18 küçük balık, 4 büyük balık bulunmaktadır. Her gün 1 adet büyük balık 1 adet küçük balığ yediğine göre, 3 gün sonra akvaryumda bulunan balık sayısı kaç olur?

\section{Çözüm Süreci}

O

Bir akvaryumda 18 küçük balık, 4 büyük balık bulunmaktadır. Her gün 1 adet büyük balık 1 adet küçük balığg

\section{KC}

yediğine göre, 3 gün sonra akvaryumda bulunan balık sayısı kaç olur? Şimdi bir akvaryumda 18 küçük balık 4

\section{HY}

büyük balık varmış, her gün 1 adet büyük balık küçük balığı yiyormuş, 3 gün sonrasını soruyor. 18...17-16-15. 15 kalır. Bu kadar da kolaya1.

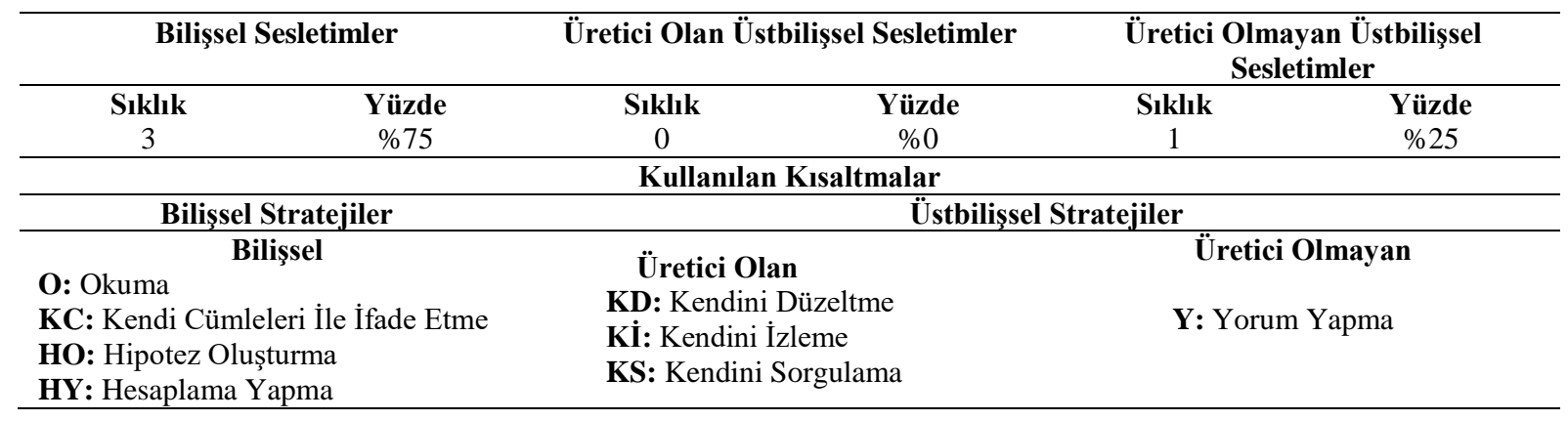


Ek A2. Sesli Düşünme Protokolü Uygulaması Örneği

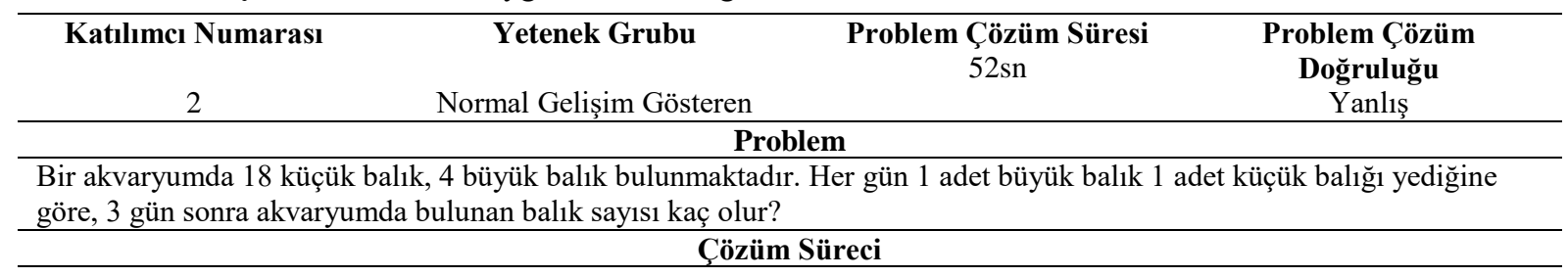

0

Bir akvaryumda 18 küçük balık, 4 büyük balık bulunmaktadır. Her gün 1 adet büyük balık 1 adet küçük balığg

\section{KC}

yediğine göre, 3 gün sonra akvaryumda bulunan balık sayısı kaç olur? Bir akvaryumda 18 tane küçük balık

varmış, şimdi 4 tane de büyük balık bulunuyormuş, her gün 1 adet büyük balık 1 adet küçük balığ yiyormuş, 3

gün sonra akvaryumda kaç balık olur. Hocam 4 tane büyük balık hergün 1 tane küçük balığı yiyormuş. Bu
HO
KD
HO
HY

durumda 18 den 3 ü çıkarız. Hayırrrr. 18 den 3 kere 4 12. 18 den 12 çıkarırız. 18 den 12 çıktı 6 balık kaldı. 6

balık kaldı.

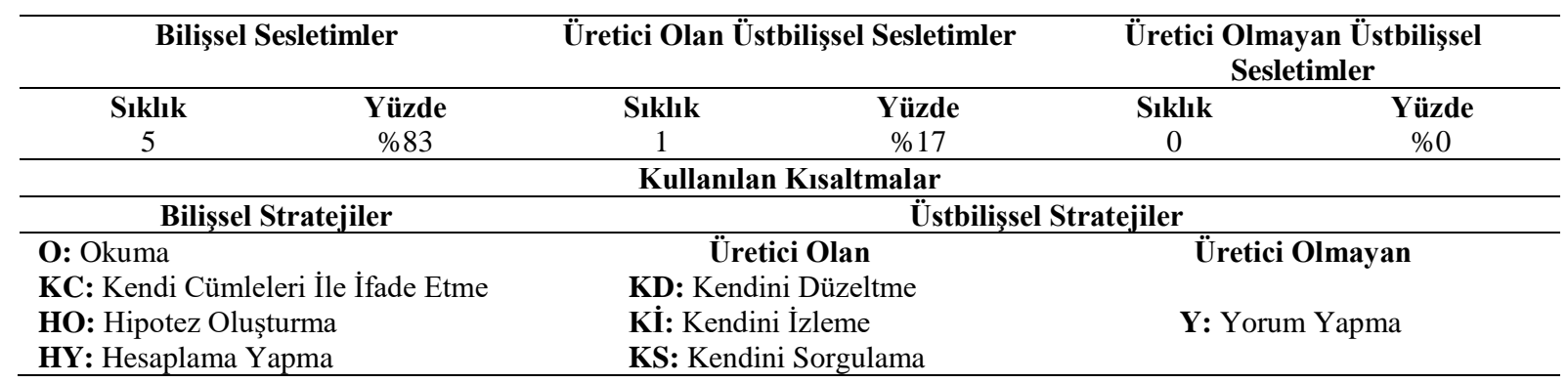


ÖĞRENME GÜÇLÜĞÜ OLAN ÖĞRENCILERINN MATEMATIK PROBLEMI ÇÖZME SÜREÇLERINININ INCELENMESI: SESLİ DÜȘÜNME PROTOKOLÜ UYGULAMASI

Ek A3. Sesli Düşünme Protokolü Uygulaması Örneği

\begin{tabular}{|c|c|c|c|}
\hline Katılımeı Numarası & Yetenek Grubu & Problem Çözüm Süresi & $\begin{array}{l}\text { Problem Çözüm } \\
\text { Doğruluğu }\end{array}$ \\
\hline 3 & Üstün Yetenekli & $170 \mathrm{sn}$ & Yanlış \\
\hline \multicolumn{4}{|c|}{ Problem } \\
\hline \multicolumn{4}{|c|}{$\begin{array}{l}\text { Bir akvaryumda } 18 \text { küçük balık, } 4 \text { büyük balık bulunmaktadır. Her gün } 1 \text { adet büyük balık } 1 \text { adet küçük balığı yediğine } \\
\text { göre, } 3 \text { gün sonra akvaryumda bulunan balık sayısı kaç olur? }\end{array}$} \\
\hline \multicolumn{4}{|c|}{ Çözüm Süreci } \\
\hline
\end{tabular}

o

Bir akvaryumda 18 küçük balık, 4 büyük balık bulunmaktadır. Her gün 1 adet büyük balık 1 adet küçük balığı

HO

yediğine göre, 3 gün sonra akvaryumda bulunan balık sayısı kaç olur? Şimdi 18 den 4 ü çıkaracağız ilk başta,

HY

bir günü bulmak için, sonra da 3 ile çarpacağız. 18 eksi 4, 14 oluyor. 14 kere 3, 4 kere 3, 12, elde var 1 oluyor, 3

Ki KC

kere, 3, ve 4 oldu. 42. Bir daha bakayım. 1 adet büyük balık 1 adet küçük balığı yediğine göre diyor. Toplam

\section{HY KS Ki}

olarak 4 kere 3, 12 olacak aslında. Neden böyle yaptım? Cevap 12. Şimdi bir daha bakayım. Şimdi 4 tane büyük

\section{KC}

balık varmış, 18 tane de küçük. Toplam olarak 1 tane yiyor, günde 1 tane yiyor. Her 4 büyük balık küçükten 1

HY

tane yediğine göre yani. Bir günde 4 tane gidiyor. 3 gün soruyor bize. Toplam olarak 12 oluyor. 4-8-12. Toplam

KD

olarak 12 çıkıyor. O zaman benim burada yapıuıın işlem ama yanlış. Akvaryumda bulunan balık sayısı kaç olur diyor. Şimdi 12 yediğine göre geriye 6 balık kalır, 4 büyük 2 küçük. Evet 6 .

\begin{tabular}{cccccc}
\hline & Bilişsel & & \multicolumn{2}{c}{ Üretici Olan Üstbilişsel } & \multicolumn{2}{c}{ Üretici Olmayan Üstbilişsel } \\
\cline { 3 - 6 } Sıklık & Yüzde & Sıklık & Yüzde & Sıklık & Yüzde \\
7 & $\% 64$ & 4 & $\% 36$ & 0 & $\% 0$ \\
\hline
\end{tabular}


Ek B. Sesli Düşünme Protokolü Kodlama Formu

Öğrenci Adı:

\section{Kişisel Bilgiler}

ÖğrenciSınıf Düzeyi:

Öğrenci Okulu:

Uygulama Tarihi:

Öğrenci Yetenek Grubu:

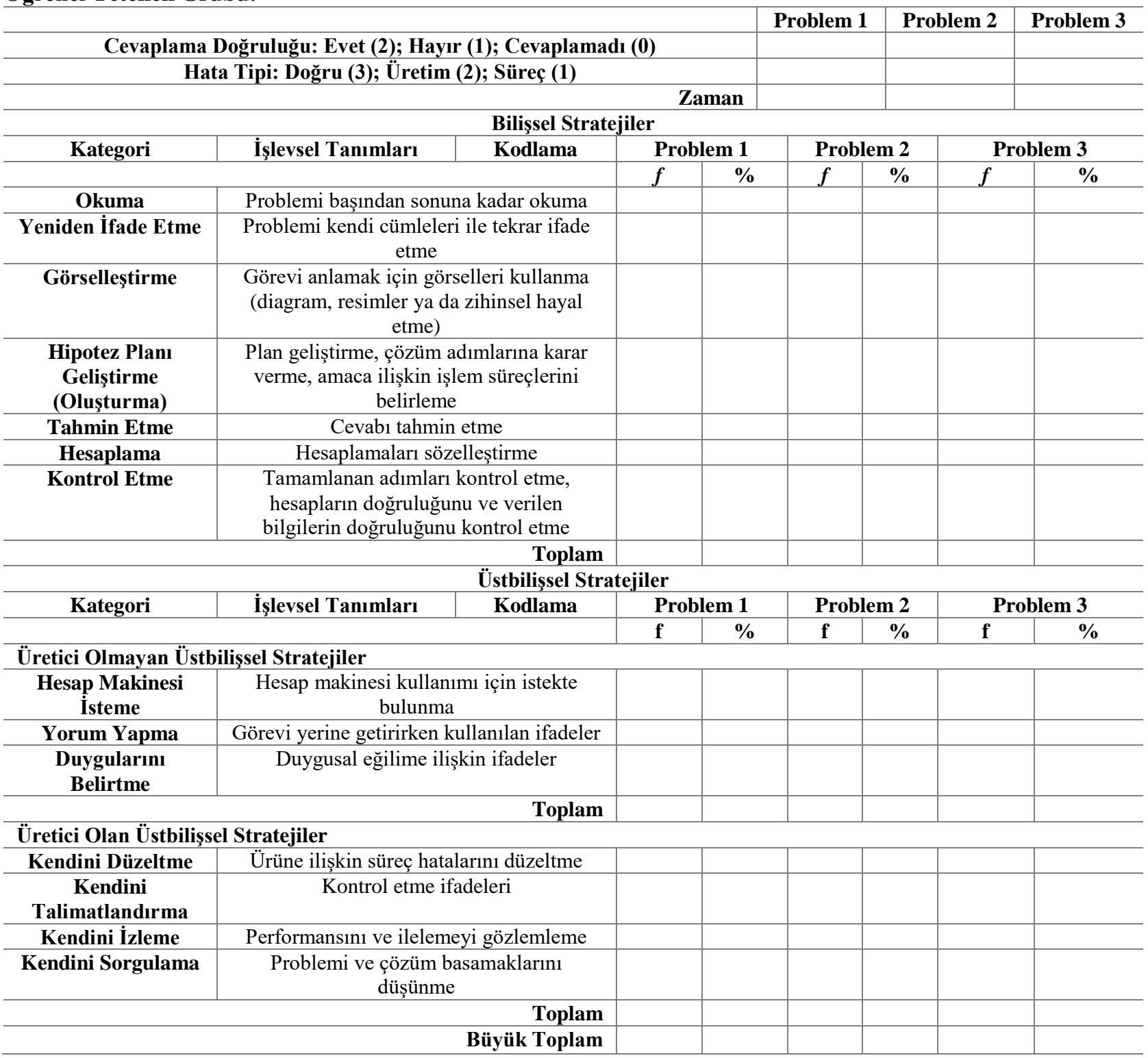

